\title{
Review
}

Ophthalmologica

\section{Corneal Collagen Crosslinking: A Systematic Review}

\author{
Nir Sorkin ${ }^{a}$ David Varssano ${ }^{a, b}$

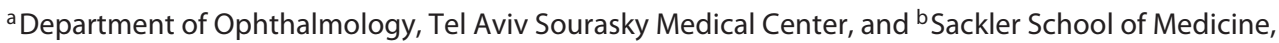 \\ Tel Aviv University, Tel Aviv, Israel
}

\section{Key Words}

Corneal collagen crosslinking $\cdot$ Keratoconus $\cdot$ Keratoectasia

\begin{abstract}
Keratoconus (KCN) is an ectatic disorder with progressive corneal thinning and a clinical picture of corneal protrusion, progressive irregular astigmatism, corneal fibrosis and visual deterioration. Other ectatic corneal disorders include: postLASIK ectasia (PLE) and pellucid marginal degeneration (PMD). Corneal crosslinking (CXL) is a procedure whereby riboflavin sensitization with ultraviolet $A$ radiation induces stromal crosslinks. This alters corneal biomechanics, causing an increase in corneal stiffness. In recent years, CXL has been an established treatment for the arrest of KCN, PLE and PMD progression. CXL has also been shown to be effective in the treatment of corneal infections, chemical burns, bullous keratopathy and other forms of corneal edema. This is a current review of $C X L$ - its biomechanical principles, the evolution of CXL protocols in the past, present and future, indications for treatment, treatment efficacy and safety.
\end{abstract}

(c) 2014 S. Karger AG, Basel

\section{Corneal Biomechanical Properties}

Biomechanical Principles

Several biomechanical terms help characterize the function of biologic materials. Elasticity is the ability of a substance to deform reversibly under stress. Viscous materials, on the other hand, flow when an external shear force is applied and do not regain their original shape when the force is removed. Viscoelastic materials exhibit characteristics of both viscosity and elasticity, resulting in energy dissipation when stress is applied. The energy lost in this process is called 'hysteresis'. Young's modulus, also known as the 'tensile modulus' or 'elastic modulus', is a quantitative measure of the stiffness of an elastic material. It is defined as the ratio of the stress along an axis over the strain along that axis. For many materials, Young's modulus is essentially constant over a range of strains. Such materials are called 'linear'. Nonlinear materials do not have a constant proportion of stress versus strain. Most materials are linear for a specific range of stress values and beyond this range lose their linear elasticity and become nonlinear.

Composite materials are materials made from two or more constituent materials with significantly different physical or chemical properties that, when combined, produce a material with characteristics different from the individual components. The individual components remain separate and distinct within the finished structure. 'Anisotropy' is the property of being directionally dependent, as opposed to 'isotropy', which implies identical properties in all directions. It can be defined as a difference, when measured along different axes, in a material's physical or mechanical properties.

David Varssano, MD

Department of Ophthalmology, Tel Aviv Sourasky Medical Center 6 Weizmann Street

Tel Aviv 64239 (Israel)

E-Mail varssano@gmail.com 


\section{Biomechanical Properties of the Normal Cornea}

In the terminology of mechanical science, the cornea is a complex anisotropic composite with nonlinear elastic and viscoelastic properties [1]. Understanding corneal macro- and microstructure allows for an understanding of its biomechanical properties. The cornea comprises 5 layers. The corneal stroma makes up $90 \%$ of corneal thickness and is the main contributor to the cornea's strength and transparency. This layer is composed of 250-400 stacked lamellae [2]. In the anterior one third of the stroma, the lamellae are more narrowly interwoven than in the posterior two thirds [3]. The lamellae are composed of type I/V collagen fibrils oriented in specific directions (depending on their location and depth). This structure, combined with the cornea's dome-like shape, converts the load created by the intraocular pressure (IOP) into a tangential tensile force carried by the stromal lamellae. While in the anterior third of the cornea collagen fibrils are more isotropic, in the central-posterior two thirds, collagen fibrils are arranged orthogonally to each other. The cornea's anisotropic tensile properties, including its resistance to the pull of the extraocular muscles, are also explained by this tridirectional fibrillar orientation $[4,5]$. Proteoglycans within the stroma surround the 35$\mathrm{nm}$ monodisperse collagen fibrils, thus creating uniform spacing of the collagen fibrils. The cornea's transverse material properties are determined primarily by the $36-$ $48 \mathrm{~mm}$ of fixed charge density associated with the presence of these organizing proteoglycans $[6,7]$. In the anteroposterior direction there is a relatively low structural resistance - contributing to the swelling properties of the cornea. The stroma is composed of $80 \%$ water, giving it viscoelastic properties $[8,9]$. The viscoelastic property of the cornea is thought to be a major contributor to corneal hysteresis $(\mathrm{CH}$; the cornea's ability to absorb energy) [10] and the corneal resistance factor (CRF; an indicator of its ability to resist external forces) [11]. Maintenance of a shape as maximally spherical as possible is essential for the cornea's refractive role. Therefore, it must distribute applied loads with great precision [12]. The biomechanical properties of the human cornea change with age. The cornea demonstrates considerable stiffening with age that could be attributed to age-related nonenzymatic crosslinking, affecting the stromal collagen fibrils $[13,14]$.

\section{Biomechanical Properties in Keratoconus}

Keratoconus (KCN) is an ectatic disorder with progressive corneal thinning and a clinical picture of corneal protrusion, progressive irregular astigmatism, corneal fibrosis and visual deterioration [15]. The preferred or- thogonal fibril orientation of the normal cornea appears to be altered in $\mathrm{KCN}$, possibly contributing to the mechanical instability [16]. It has been suggested that only the anterior $200 \mu \mathrm{m}$ of the cornea are affected in KCN [17]. KCN may involve a disturbance of the balance between proteolytic breakdown and repair [18]. Both the concentration and the activity of the crosslinking enzyme lysyl oxidase have been shown to be significantly reduced in $\mathrm{KCN}$ corneas [19]. Mechanically, the KCN cornea shows a substantial reduction in stiffness [20]. A modelbased analysis of a KCN cornea has shown that the shape distortion in $\mathrm{KCN}$ is affected by three factors: (1) localized thinning; (2) reduction in the tissue's meridian elastic modulus, and (3) reduction in the shear modulus perpendicular to the corneal surface [21]. The point of maximal stress on the KCN cornea was shown to be at the center of the corneal bulge - more specifically in areas of maximal thinning. The cornea's biomechanical properties can be measured in vivo using the Reichert Ocular Response Analyzer (ORA; Reichert, Inc., Buffalo, N.Y., USA). The device measures the corneal force/displacement relationship using an air jet to apply pressure to the cornea. During the first phase of measurement, the air jet causes the cornea to flatten and assume a concave shape. Shortly after, the air pressure decreases, causing the cornea to return to its basic formation. The measurement is performed during a very short time period (approx. 20 $\mathrm{ms}$ ) to avoid the influence of momentary IOP (and other ocular parameter) changes. The changes in corneal shape throughout the measurement period are recorded using an electro-optical sensor which monitors the central $3 \mathrm{~mm}$ of the cornea. This enables in vivo measurement of $\mathrm{CH}$ and the CRF [10]. In KCN corneas, $\mathrm{CH}$ and the CRF have been shown to be significantly decreased when compared with non-KCN corneas [11, 22-24].

\section{Biomechanical Properties in Other Keratoectatic Disorders}

In addition to $\mathrm{KCN}$, corneal ectasia is a feature of several other disorders, including: post-LASIK ectasia (PLE) and pellucid marginal degeneration (PMD).

Ectasia following LASIK is rare, with an incidence of approximately $0.66 \%$ [25]. It may be apparent immediately following LASIK surgery or years after, generally occurring within 2 years of surgery [26,27]. Clinically, it is manifested as two distinct entities: the first is a central forward bowing with minimal irregular astigmatism, and the second is a $\mathrm{KCN}$-like ectasia with paracentral thinning and resultant significant irregular astigmatism. Histopathologic analysis of eyes with PLE has shown features 
similar to KCN. Changes included: forward protrusion of both anterior and posterior corneal surfaces, epithelial detachment, Bowman's membrane breakage and folding and irregular lamellae $[28,29]$. Forward movement of the posterior corneal lamella appears to occur routinely following LASIK in a nonprogressive manner [30, 31]. Posterior corneal bulging following LASIK was suggested to be caused by IOP [31]. Other studies did not find such an effect of IOP [32]. Guirao [33] described a model used to examine the influence of myopic LASIK on corneal elastic properties. Based on this model, it was proposed that corneal thinning caused by ablation produces an elastic deformation of the posterior corneal surface. The degree of deformation was found to be dependent on intrinsic corneal parameters (curvature, Young's modulus and thickness) and extrinsic parameters (IOP and ablation profile).

PMD is a rare ectatic disorder which typically affects the inferior or superior peripheral cornea in a crescentic fashion. Histopathologically, the degeneration appears in a region close to the limbus. This region shows a replacement of Bowman's layer with a collagenous pannus. The anterior stroma contains degenerated collagen fibrils with very large proteoglycans. The lamellae are fused and keratocytes appear like fibroblasts [34]. This suggests that PMD could be related to a disorder in the synthesis of collagen fibrils. We were unable to find a report of PMD biomechanics in the literature.

\section{Chemistry of Crosslinking}

\section{Crosslinking in Polymers}

Crosslinking is the creation of bonds that connect one polymer chain to another. The bonds can be covalent or ionic. A polymer is defined as a chain of monomeric material - either a synthetic polymer or a biologic molecule (such as a protein). Crosslinking of polymers changes their physical properties. For example, crosslinking a rubber molecule will cause a decrease in its flexibility and an increase in its rigidity and melting temperature [35]. Crosslinking is used in bioengineering to strengthen materials, as well as in dentistry to harden filling materials $[36,37]$.

\section{Early Applications of Crosslinking}

In 1992, Hettlich et al. [38] investigated possible ways to perform lens refilling following phacoemulsification. They developed a method which included the injection of a monomer into the lens capsule, followed by intracapsular polymerization of the material by exposure to light
$(400-500 \mathrm{~nm})$. The substance did not seem to cause significant damage to surrounding tissues [38]. This method is an early example for the use of light energy to induce intraocular structural changes.

Riboflavin, also known as vitamin $\mathrm{B}_{2}$, is an easily absorbed, colored micronutrient with a key role in maintaining health in humans and animals. Following exposure to ultraviolet (UV)A radiation, riboflavin molecules absorb energy and reach an excited state. In its excited state, riboflavin can either produce radicals or singlet oxygen molecules, depending on the availability of oxygen $[39,40]$. These highly active molecules can induce covalent bonds, thus crosslinking collagen fibers (or other corneal molecules such as proteoglycans and nucleic acids) [41].

Riboflavin was initially described as an active component (together with fibrinogen) in a light-activated corneal tissue glue, excited using blue-green (488-514 nm) argon laser light $[42,43]$.

\section{Evolution of Riboflavin: UVA Corneal Collagen Crosslinking}

\section{First Steps}

In the 1970s, Siegel et al. [44, 45] discussed crosslinking reactions whereby lysyl oxidase catalyzed the formation of crosslinking aldehydes in collagen and elastin. In 1997, Spoerl et al. [46] used a similar principle to attempt an induction of corneal crosslinking (CXL), aiming to increase corneal stiffness. They had several porcine eye test groups treated with UV light alone/0.5\% riboflavin alone/ riboflavin with UV light or blue light or sunlight/glutaraldehyde and Karnovsky's solution. Examination of the stress-strain properties in each of the groups showed that riboflavin and UV light as well as glutaraldehyde or Karnovsky's solution led to increased corneal stiffness [46]. This technique was later studied in vivo by Wollensak et al. [47] on 22 progressing KCN patients. Following central removal of the epithelium, photosensitizing riboflavin drops were applied and the eyes exposed to UVA ( 370 $\mathrm{nm}, 3 \mathrm{~mW} / \mathrm{cm}^{2}$ ) at a $1-\mathrm{cm}$ distance for $30 \mathrm{~min}$. Clinical follow-up showed that $\mathrm{KCN}$ stopped progressing in all eyes, and in $70 \%$ of the eyes a regression in keratometric and refractive values had been observed [47].

\section{Duration of the Treatment Steps: The Dresden \\ Protocol}

The standard treatment protocol, commonly referred to as the 'Dresden protocol' (owing to the fact it was first
Sorkin/Varssano 
described by Wollensak et al. [47] from the Technical University of Dresden), includes the following steps:

- Anesthetizing the eye with a topical anesthetic

- Removal of the central 7-9 mm of the epithelium

- Application of a $0.1 \%$ riboflavin 5-phosphate and $20 \%$ dextran solution to the deepithelized surface every $5 \mathrm{~min}$ for $30 \mathrm{~min}$

- Exposure to UVA $\left(370 \mathrm{~nm}, 3 \mathrm{~mW} / \mathrm{cm}^{2}\right)$ radiation for a duration of $30 \mathrm{~min}$ with continued application of the above solution every $5 \mathrm{~min}$

- Application of topical antibiotics and a soft bandage contact lens with good oxygen permeability

\section{Accelerated CXL}

An irradiance of $3 \mathrm{~mW} / \mathrm{cm}^{2}$ with a treatment zone of $9 \mathrm{~mm}$ for a duration of $30 \mathrm{~min}$ results in a total energy of $3.4 \mathrm{~J}$ or $5.4 \mathrm{~J} / \mathrm{cm}^{2}$. If one wants to make an effort to shorten the duration of the procedure, it is possible to use a higher-intensity light for a shorter period of time; an irradiance of $10 \mathrm{~mW} / \mathrm{cm}^{2}$ for a duration of $9 \mathrm{~min}$ was shown to have similar rigidity results in porcine corneas [48]. A large ex vivo study of porcine eyes examined the response to irradiances between 3 and $90 \mathrm{~mW} / \mathrm{cm}^{2}$ with illumination times between 30 and $1 \mathrm{~min}$, respectively. It was shown that irradiation levels up to $45 \mathrm{~mW} / \mathrm{cm}^{2}$ produced significantly stiffer corneas when compared with nonirradiated controls. But levels of $50 \mathrm{~mW} / \mathrm{cm}^{2}$ and above (with their respective time periods) did not show significantly greater stiffness [49]. An ex vivo study compared ultrafast CXL (30 s of UVA exposure) using a custom CXL agent (by PriaVision Inc., Menlo Park, Calif., USA) with a standard 30-min riboflavin CXL in porcine eyes. Both groups showed similar stiffness changes (measured using surface wave elastometry) [50]. In human eyes, an ex vivo study compared CXL with standard $\left(3 \mathrm{~mW} / \mathrm{cm}^{2}\right.$ for $\left.30 \mathrm{~min}\right)$ versus the accelerated $(9 \mathrm{~mW} /$ $\mathrm{cm}^{2}$ for $10 \mathrm{~min}$ ) protocol. Corneal stiffness results were not different between the groups [51]. An evaluation of endothelial cell changes following accelerated CXL (18 $\mathrm{mW} / \mathrm{cm}^{2}$ for $5 \mathrm{~min}$ ) in $36 \mathrm{KCN}$ patients showed significant differences in endothelial cell density and morphology parameters. Those parameters returned to preoperative values at 3-6 months after CXL. This showed that while endothelial cells do recover safely following the accelerated procedure, there is clear evidence of endothelial effects following accelerated CXL [52]. A comparative clinical study included 21 patients with $\mathrm{KCN}$, treated with accelerated CXL $\left(7 \mathrm{~mW} / \mathrm{cm}^{2}\right.$ for $\left.15 \mathrm{~min}\right)$ in one eye and with standard CXL ( $3 \mathrm{~mW} / \mathrm{cm}^{2}$ for $30 \mathrm{~min}$ ) in the fellow eye. A mean follow-up of 46 months showed no progres- sion of $\mathrm{KCN}$ in any of the groups with similar improvement in visual acuity and keratometric parameters and no evidence of endothelial damage [53]. A series of $23 \mathrm{pa}$ tients undergoing more rapid CXL $\left(9 \mathrm{~mW} / \mathrm{cm}^{2}\right.$ for 10 $\mathrm{min}$ ) showed favorable outcomes with no evidence of endothelial cell density changes during a 6-month followup [54]. Currently, there is no uniform protocol for accelerated CXL and no large clinical trials investigating this method.

\section{Instruments}

The initial in vivo CXL study by Wollensak et al. [47] in 2003 used 370-nm UV diodes (Roithner Lasertechnik, Vienna, Austria) with a potentiometer regulating the voltage. Three 1.3-volt accumulators were used as a power generator. Before each treatment, the desired irradiance of $3 \mathrm{~mW} / \mathrm{cm}^{2}$ was controlled with a UVA meter ( $\mathrm{La}-$ serMate-Q; LASER 2000, Wessling, Germany) at a 1-cm distance and, if necessary, regulated with the potentiometer [47].

Several CXL instruments are in use today for standard collagen CXL. The XLink ${ }^{\mathrm{TM}}$ (Optos, Dunfermline, UK) has an intensity range of $0.5-5 \mathrm{~mW} / \mathrm{cm}^{2}$ and is used in standard 30-min CXL procedures. The CBM Vega XLink Crosslinking System (Carleton Optical, Chesham, UK), designed for standard 30-min CXL, was used effectively in several clinical studies $[55,56]$. The LightLink CXL ${ }^{\mathrm{TM}}$ (LightMed, San Clemente, Calif., USA) has a wide range of irradiance between 0.5 and $30 \mathrm{~mW} / \mathrm{cm}^{2}$, allowing a choice of various treatment protocols from 3 to $30 \mathrm{~min}$ length. Several CXL instruments for accelerated CXL have been introduced. The UV-X ${ }^{\mathrm{TM}} 2000$ Crosslinking System (IROC Innocross, Zurich, Switzerland) has a maximal intensity of $12 \mathrm{~mW} / \mathrm{cm}^{2}$ and can be used for a 10-min accelerated CXL procedure. The KXL ${ }^{\mathrm{TM}}$ System (Avedro, Waltham, Mass., USA) is able to produce a light intensity of $30 \mathrm{~mW} / \mathrm{cm}^{2}$, enabling ultrafast accelerated CXL with less than 3 min of UVA exposure. It appeared to be effective in a small group of KCN patients when combined with an LASEK procedure [57], and also for treatment of infectious keratitis in cats [58].

\section{Epithelium On/Off}

The standard CXL protocol includes large deepithelization of the cornea (epi-off CXL). This is due to the fact that riboflavin is a macromolecule with inadequate corneal penetration ability $[59,60]$. Deepithelization could serve as a potential source of postoperative infections, a complication previously reported [61-65]. In addition, the period of epithelial healing is associated with intense 
postoperative pain [66] and a delay in the return to daily activities. Performing a transepithelial CXL (epi-on CXL) could theoretically reduce these complications.

Animal studies have shown that epi-on CXL does produce increased corneal stiffness $[67,68]$. When compared with epi-off CXL, epi-on CXL resulted in only one fifth to one third of the increase in corneal stiffness $[67,69]$. It was also shown that the treatment depth in epi-on CXL is greatly reduced when compared with epi-off CXL [69]. Following epi-off CXL in rabbit corneas, measurement of maximal stress was $35.9 \%$ higher and Young's modulus $15.4 \%$ higher when compared with a similar epi-on CXL rabbit group [68]. These results raised the question whether the reduced effect of epi-on CXL is enough to maintain clinical stability. Human in vivo comparison of the two methods demonstrated an inferior effect of epion CXL. There were no significant stromal changes (such as a decrease in anterior keratocyte density, evident stromal edema and keratocyte activation) following epi-on CXL. All these changes were significantly evident following epi-off CXL [70]. A study performed on 20 eyes compared epi-off CXL with CXL performed using partial epithelial removal in a grid-like pattern. Evaluation of treatment depth using OCT showed that areas of an intact epithelium appeared to block penetration of riboflavin into the anterior corneal stroma [71]. Several small prospective studies evaluated the clinical value of epi-on CXL. Their results were variable. One prospective 20-patient series showed statistically significant improvement in uncorrected and corrected visual acuity and topography-derived keratometry, cone apex power and higherorder aberrations with no apparent progression of $\mathrm{KCN}$ [72]. A recently published 2-year prospective study of 26 eyes undergoing epi-on CXL showed that after relative improvement during the first 6 months after CXL, visual acuity parameters returned to baseline at 1 year. At 2 years after CXL, keratometric and pachymetric indices worsened compared with the pre-CXL values [73].

Several adjunctive methods were studied in an effort to increase riboflavin penetration through an intact epithelium. The use of benzalkonium chloride (BAC) and ethylenediaminetetraacetic acid (EDTA) as a means of weakening epithelial tight junctions has been evaluated. The use of BAC in rabbit eyes was shown to increase the riboflavin absorption coefficient through an intact epithelium. Nevertheless, the absorption coefficient achieved was only $37 \%$ that of epi-off absorption [74]. Slightly different results were shown in a very similar study, where the addition of BAC increased the riboflavin absorption coefficient in epi-on CXL to a level similar to a standard epi-off CXL. Moreover, a biomechanical analysis of treated corneas showed no significant differences in resultant corneal stiffness in the two groups [75]. A prospective clinical study on 51 eyes, using epi-on CXL with the addition of BAC and EDTA, showed a limited but favorable effect of BAC/EDTA-assisted epi-on CXL on keratoconic eyes. The treatment effect was compared with the nontreated contralateral eyes for a duration of 12 months. While favorable, the treatment effect in this study appeared to be less pronounced than described in the literature after epi-off CXL [76]. Similar results were shown over a period of 18 months for 53 eyes undergoing BACassisted epi-on CXL [77].

Riboflavin is a water-soluble, negatively charged molecule with a molecular weight of $376.40 \mathrm{~g} / \mathrm{mol}$, which makes it a good candidate for iontophoresis. Iontophoresis appears to enhance transepithelial riboflavin penetration [78]. Epi-on CXL using iontophoresis showed good clinical results in terms of reduced astigmatism and keratometric values with improved best-corrected visual acuity (BCVA) in a prospective series of 22 eyes [79]. Other methods, investigated in rabbit corneas, include: phonophoresis (ultrasound-assisted drug penetration) and a biocompatible riboflavin-based nanoemulsion system. Both have shown potential in increasing transepithelial penetration of riboflavin [80, 81]. Lastly, the use of a hypoosmolar riboflavin solution (with $0.44 \% \mathrm{NaCl}$ ) was also investigated and appears to contribute to the transepithelial absorption of riboflavin [74].

Epi-on CXL is especially appealing for use in the pediatric population. Pediatric patients are more sensitive to the possible effects of epithelial debridement such as postoperative pain, temporary visual deterioration and increased risk of infection and haze. As in the adult population, there are no large-scale prospective trials evaluating epi-on CXL in children. Results of existing studies are conflicting. A recently published 1-year follow-up of 22 eyes of children treated with epi-on CXL showed significant improvement in visual acuity parameters and keratometric values [82]. A retrospective comparison of epion with epi-off CXL in 39 pediatric KCN patients (23 epioff, 16 epi-on) showed no significant differences between the groups in any of the clinical parameters evaluated (visual acuity and topographic parameters). The epi-on CXL group showed reduced postoperative pain and no postoperative corneal edema [83]. Different results were shown in a prospective 18-month follow-up of 13 eyes of children, where epi-on CXL did not appear to halt KCN progression despite a significant improvement in corrected distance visual acuity (CDVA) [84]. 
Other CXL Methods in Corneal Collagen

Riboflavin and UVA is the universally accepted method today for CXL. However, photochemical CXL with other agents is under research. In one study, chemical derivatives of the photosynthetic pigments (chlorophylls and bacteriochlorophylls) introduced into rabbit corneas in vivo and ex vivo were excited using near-infrared illumination. The result was stiffening of the treated corneas. It is proposed that photoexcitation caused these materials to generate $\mathrm{O}_{2}{ }^{-}$and $\cdot \mathrm{OH}$ radicals, which promoted protein crosslinking and the resultant stiffening [85]. Recently, the use of Rose Bengal dye excited by green light has shown to significantly increase rabbit corneal stiffness, using a rapid treatment protocol ( $12 \mathrm{~min}$ in total) with no apparent toxicity to keratocytes. It was suggested as a potential future option for CXL of corneas thinner than 400 $\mu \mathrm{m}[86]$. The use of femtosecond laser to excite riboflavin molecules has shown a stiffening effect similar to UVA excitation when used in vitro to crosslink collagen hydrogels [87].

Other methods of purely chemical CXL were also investigated. These have potential advantages over Riboflavin-UVX, such as avoidance of radiation toxicity and a more simple delivery method of the active agent. The most widely used corneal crosslinkers are probably tissue fixatives such as formaldehyde, glutaraldehyde and Karnovsky's solution (discussed above). These agents cause tissue stiffening through CXL, thus fixating it for pathologic analysis. Unfortunately, these agents are toxic in vivo and are not used clinically [88]. Genipin is an active molecule derived from the plant Gardenia jasminoides. It was shown to produce a CXL effect similar to standard CXL in porcine eyes, with minimal endothelial toxicity and no need for irradiance [89]. In recent years, the use of $\beta$-nitroalcohols has been suggested as a promising CXL method. These agents function as both formaldehyde and nitrite donors under physiologic conditions, thus enabling CXL of collagenous tissue $[90,91]$. Due to their widespread industrial use, their safety profile has been studied and was found to be favorable [92].

\section{Results}

\section{Keratoconus}

Histology and Morphology

In 2006, Seiler and Hafezi [93] described the formation of a stromal demarcation line following CXL at a depth of approximately $300 \mu \mathrm{m}$, representing the interface between treated and untreated cornea. They speculated the demarcation line is a result of refractive and reflective differences between treated and untreated stroma [93]. Shortly after the application of a riboflavin plus dextran $25 \%$ solution, corneal thickness decreases [94]. This decrease in thickness may be the cause of the collagen fibril disorganization observed following CXL [95]. Histologic evaluation of rabbit corneas following CXL showed a pattern of extensive keratocyte loss throughout the entire stroma with accompanying endothelial loss - these were apparent in the central irradiated zone. The anterior stroma showed a pattern of lacunar edema in the space where apoptosed keratocytes used to be. The areas adjacent to the treated zone had diffuse edema. This difference in edema pattern between the treated zone and the areas adjacent to it can serve as an explanation for the formation of the above-described demarcation line. By week 6 after the operation, the cellular structure appears to normalize [96]. Others reported the keratocyte loss to be more prolonged - up to 30 months postoperatively [97]. In vivo studies using confocal microscopy showed similar findings following CXL, with keratocyte loss and stromal edema. In addition, a superficial nerve layer loss was observed [98]. Stromal edema persists for 4-6 weeks and then gradually resolves, with keratocyte repopulation and stromal collagen compaction. This transient edema causes the known decrease in visual acuity during the first postoperative months [99]. While central stromal keratocyte loss in the treated area persists at 36 months postoperatively, nerve regeneration starts at 1 month and continues past 36 months. A small percentage of patients demonstrate endothelial damage with gradual healing completed at 1 year postoperatively [98]. Collagen fiber diameter increases following CXL, with a reorganization of collagen fibrils in a parallel, lamellar structure similar to a non-KCN cornea (and opposed to a KCN cornea). This is accompanied by an increase in interfibrillar spacing, which also gives the cornea after CXL a structure more similar to a non-KCN cornea [100]. The increase in collagen fiber diameter is more pronounced in the anterior stroma, where a maximal treatment effect is achieved [101]. Macroscopically, the cornea shows significant flattening following CXL, with a reduction in K values [102].

\section{Biomechanics}

CXL stiffens the cornea. Increased corneal rigidity has been documented both in animal $[46,103,104]$ and human ex vivo $[105,106]$ studies, showing an increase of $328.9 \%$ in rigidity and by a factor of 4.5 in Young's modulus on human corneas. Interestingly, in porcine corneas, rigidity and Young's modulus increased by only $71.9 \%$ 
and a factor of 1.8, respectively [105]. This difference was attributed to the significantly greater thickness of porcine corneas and their reduced absorption of UVA [105].

As discussed above, the ORA instrument allows for noncontact in vivo evaluation of corneal biomechanic parameters. One single-center, prospective, randomized, controlled clinical trial evaluated 69 eyes after CXL in vivo (46 KCN and $23 \mathrm{PLE}$ ). $\mathrm{CH}$ and CRF were measured using the ORA and analyzed in a treatment, sham control and fellow eye control group during 12 months. Despite an increase in CRF at 1 month, there were no statistically significant changes in $\mathrm{CH}$ and $\mathrm{CRF}$ measurements 1 year after CXL [107]. Similar results were found in two other prospective in vivo studies of similar size, performed using the ORA $[23,108]$. Several explanations were proposed for the lack of change in biomechanic parameters in vivo versus the obvious changes observed in vitro. One is the fact that different measuring systems were used (e.g. ORA vs. strip extensometry). Another is related to the fact that $\mathrm{KCN}$ cornea is extremely irregular and thus may exhibit great variability in resistance to deformation by the ORA depending on small location changes, and therefore averaging ORA measurements may not provide an assessment that is accurate enough [108]. Corneas following CXL also show an increased resistance to enzymatic digestion [109] and to swelling [110].

\section{Clinical Results}

As previously stated, in 2003 Wollensak et al. [47] were the first to describe the clinical effect of CXL on $22 \mathrm{KCN}$ eyes during a 2- to 4-year follow-up period. All eyes experienced a halt in KCN progression. Visual acuity improved in 15 of the 22 eyes, and flattening of the maximum keratometry value $\left(\mathrm{K}_{\max }\right)$ by 2 diopters was seen in 16 of the 22 eyes [47]. Since then, numerous studies have evaluated the clinical effect of CXL in the treatment of KCN. The only randomized, controlled clinical trial to date randomized 66 eyes of 49 progressive KCN patients into CXL treatment and control groups. The 1-year results showed that $\mathrm{K}_{\max }$ had been significantly reduced at all follow-up periods, with an average decrease of 1.45 diopters at 12 months. A trend toward improvement in BCVA was also observed. Analysis of the control group showed a continuous deterioration in $\mathrm{K}_{\max }$ and BCVA [111].

Other small prospective trials showed a significant improvement in visual acuity and keratometric parameters. Some also showed an improvement in refractive and topographic parameters. Their results are shown in table 1 .
Long-Term Studies

The Siena Eye Cross Study, a phase II nonrandomized open trial, examined the effect of CXL on progressive KCN. The results for 44 study eyes completing a minimum follow-up of 48 months were analyzed. All eyes treated showed KCN stability; $65 \%$ of the fellow eyes showed a mean progression of 1.5 diopters in corneal power during the first 24 months of follow-up, and required CXL. In the treated eyes, the improvement in keratometric values, visual acuity and coma aberrations was maintained following 48 months of follow-up [123]. Two other prospective studies evaluated the longer-term effect of CXL. One was a 5-year study including 40 eyes [124] and the other a 3-year study including 55 eyes [125]. Both studies found CXL results to be completely stable through the follow-up period with no apparent safety issues.

\section{Retrospective Studies}

Two very large retrospective reports were aimed at analyzing the long-term effect of CXL. One included 241 eyes followed up for up to 6 years [126] and the other included 400 eyes followed up for up to 4 years [127]. It is important to note that the majority of patients in each of these trials had not reached a 2-year follow-up period. Only 9.15 and $1.75 \%$, respectively, of the patients reached a 4-year follow-up period in each of the studies. Therefore, their ability to evaluate long-term effects is unclear. Despite the low number of long-term follow-ups, the results indicate long-term stabilization and improvement after collagen CXL [126].

\section{Results of Combined Photorefractive Surgery and} CXL

The addition of photorefractive surgery to the CXL procedure in patients with $\mathrm{KCN}$ can improve visual and refractive outcomes in addition to the prevention of $\mathrm{KCN}$ progression. A study comparing the use of same-day CXL and photorefractive keratectomy (PRK) with the use of sequential CXL and PRK performed 6 months later was conducted on $325 \mathrm{KCN}$ eyes (127 eyes underwent the same-day procedure and 192 eyes underwent the sequential procedure). A follow-up period of 36 months (range: 24-68 months) showed that the same-day procedure was significantly more efficient in improving visual acuity, keratometric parameters, spherical equivalent and corneal haze scores [128]. Several smaller prospective series (ranging from 12 to 31 eyes each) showed combined PRK and CXL to be effective both in improving visual acuity and refractive error and in regressing $\mathrm{KCN}$ parameters [129-132]. One comparative contralateral eye series inDOI: 10.1159/000357979
Sorkin/Varssano 
Table 1. Prospective studies of CXL for KCN

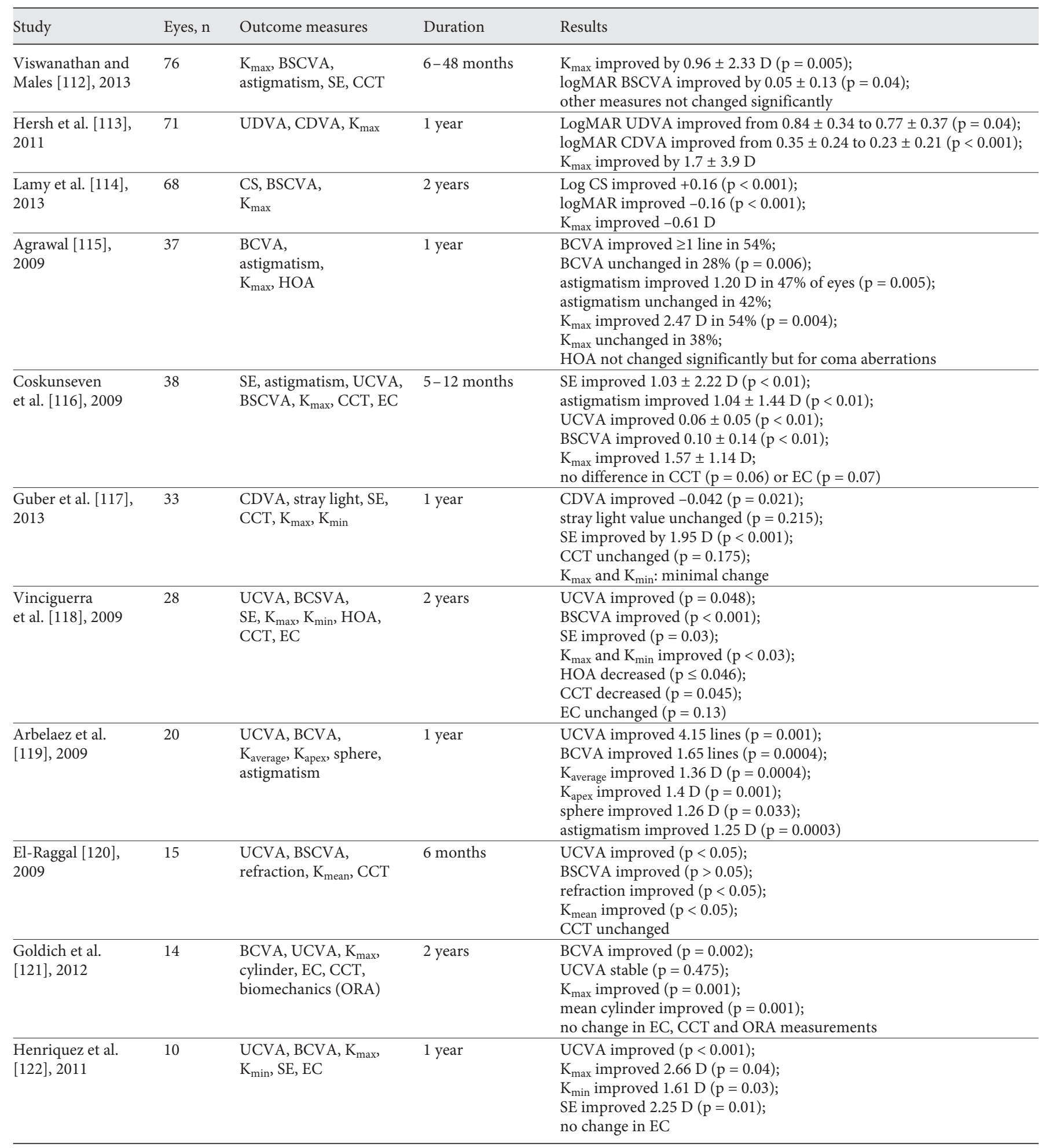

BSCVA = Best spectacle-corrected visual acuity; $\mathrm{SE}=$ spherical equivalent; $\mathrm{CCT}=$ central corneal thickness; logMAR = logarithm of the minimal angle of resolution; VA = visual acuity; UDVA = uncorrected distance visual acuity; CS = contrast sensitivity; HOA = high-order aberrations; UCVA = uncorrected visual acuity; $\mathrm{EC}=$ endothelial cell count. 
cluding 17 patients with progressive $\mathrm{KCN}$ compared treatment with combined PRK and CXL with CXL alone. For each patient in the study, the eye with the greatest $\mathrm{KCN}$ progression was chosen to receive combined treatment, while the fellow eye received CXL alone. While, in both groups, keratometric parameters improved significantly, the improvement in visual acuity, refractive error and coma aberrations was more prominent in the combined PRK plus CXL group, showing statistical significance in all parameters [133]. It should be stated here that since the eyes in the combined PRK plus CXL group had greater KCN progression, the baseline characteristics were different between the groups and, therefore, the significant advantage shown for the PRK plus CXL group was also a result of those differences.

Results of Combined Intracorneal Ring Segments and CXL

While CXL has been shown to halt $\mathrm{KCN}$ progression, its effect on visual rehabilitation may be insufficient. Intracorneal ring segments (ICRS) produce rapid and substantial improvement in visual parameters but do not halt KCN progression [134]. Therefore, combining the two procedures can theoretically produce better results. A retrospective comparative analysis performed on 66 eyes showed that 1 year postoperatively, the 34 eyes treated with ICRS had better visual and keratometric results than the 32 eyes treated with a combination of CXL and ICRS [135]. A similar prospective study conducted over a 2-year follow-up period (39 eyes) showed no difference between patients treated with ICRS alone and patients treated with CXL followed by ICRS implantation 3 months later. Both groups showed similar results in terms of refractive, topographic, pachymetric, tonometric and corneal biomechanical parameters [136].

CXL in the Pediatric Population

Diagnosis of KCN at a younger age constitutes a poor prognosis regarding progression of the disease and the future need for a corneal transplant [137]. The prospective, nonrandomized, phase II open trial - the Siena CXL Pediatrics trial - included 152 patients aged 18 years or younger (10-18 years) suffering from progressing $\mathrm{KCN}$ [138]. A 3-year follow-up after epi-off CXL showed significant improvement in both visual acuity and keratometric values and a reduction in coma aberrations. Similarly, positive results were demonstrated in two smaller prospective pediatric trials $[139,140]$.

\section{Other Results}

The use of CXL for the treatment of KCN has been shown to significantly improve quality of life even 3 years following the procedure. This was shown using visionspecific quality-of-life questionnaires. CXL specifically improved the 'mental health', 'driving' and 'dependency' subscores in the vision-specific quality-of-life questionnaire [141].

\section{Other Keratoectatic Disorders}

Ectasia following Photorefractive Surgery

Progressive corneal ectasia is a well-known possible complication of photorefractive surgery [25, 142]. Morphological changes following CXL in corneas with PLE were found to be identical to changes in $\mathrm{KCN}$ corneas following CXL [143]. Several small, prospective clinical studies have evaluated CXL for PLE and found that visual acuity and keratometric measures either significantly stabilized or improved. All those studies had only 1 year of follow-up [144-147]. A retrospective study evaluated 26 eyes with PLE (23 eyes) and with ectasia after PRK ( 3 eyes) during a 2-year follow-up period. There was significant improvement in CDVA, $\mathrm{K}_{\max }$ and several topographic indices of corneal regularity (such as index of surface variance, index of vertical asymmetry, KCN index and central $\mathrm{KCN}$ index) [148].

In 2011, Kanellopoulos and Binder [149] reported their data on a combination treatment using simultaneous CXL and PRK in patients with PLE. The goal was to use PRK to improve visual outcomes by normalizing the corneal surface, reducing irregular astigmatism and potentially reducing the refractive error - in addition to the corneal stabilization effect of corneal CXL. Twenty-seven of 32 eyes had an improvement in uncorrected distance visual acuity and CDVA to 20/45 or better at the end of follow-up; 4 eyes showed some topographic improvement but no improvement in CDVA; 2 of the 32 eyes had corneal ectasia progression after the intervention and 1 of the treated eyes subsequently required a penetrating keratoplasty [149]. This treatment protocol is commonly referred to as the 'Athens protocol'.

\section{Pellucid Marginal Degeneration}

Being a rare condition, PMD has been evaluated much less than KCN, especially with regard to CXL treatment. A major difference between PMD and $\mathrm{KCN}$ is the location of maximal corneal thinning and steepening. In $\mathrm{PMD}$, corneal thinning is more peripheral than in $\mathrm{KCN}$ [150]. A study examining the peripheral effect of CXL, using OCT evaluation of the stromal demarcation line, 
showed that the depth of the CXL effect $3 \mathrm{~mm}$ away from the center of the cornea decreases to $65 \%$ of the central depth. Therefore, it was concluded that the intended depth of CXL using current light sources is achieved only within the central area of the cornea, and in order to provide CXL to the peripheral cornea, the ultraviolet beam either should have an improved intensity profile or may have to be decentered [151]. Two prospective studies evaluated the effect of CXL on the peripheral cornea. One was a randomized, controlled clinical trial examining the 1 -year effect of CXL in 99 eyes with KCN and PLE. This trial showed a decreased flattening effect following CXL in peripheral cones when compared with flattening results for central cones [152]. The other study was a prospective 2-year series evaluating $68 \mathrm{KCN}$ eyes. This study found a significant difference in visual acuity parameters between centrally and paracentrally located apices in favor of the central apices [114].

One series of 13 eyes with PMD following CXL procedures showed stable keratometric results and good visual acuity in all eyes except one [153]. A few case reports describing CXL for PMD have been published. All showed improvement and/or stabilization of visual acuity and keratometric parameters [154-156]. A study examining the effect of combined PRK and CXL on corneal ectasia included 6 eyes with PMD and 6 eyes with KCN. Results were only given for the entire cohort as a whole, and therefore they are less significant for evaluation of PMD. Nevertheless, the group as a whole showed a significant improvement in visual acuity, keratometry and astigmatism parameters [132].

\section{Other Indications for Riboflavin-UVX Collagen CXL}

\section{Corneal Infections and Chemical Burns}

Evidence of the antimicrobial activity of riboflavin and UVA was initially described by Tsugita et al. [157] in 1965. They demonstrated its ability to damage viral DNA in a virus infecting tobacco plants. The combination of riboflavin with UVA or the use of UVA by itself has the ability to damage nucleic acids and thus is directly antimicrobial [158]. In addition, CXL has been shown to increase the cornea's resistance to enzymatic digestion [109]. Thus, CXL treatment of corneas with infective keratitis can improve their ability to resist proteolytic enzymes secreted by infective microorganisms. The proteolytic enzymatic activity is the cause of clinical corneal melting during and following corneal infections. In vitro studies have demonstrated a good bactericidal effect of combined riboflavin and UVA on several bacterial species which are known pathogens in bacterial keratitis $[159,160]$. The effects on fungal and acanthamoebic activity in vitro were less favorable, showing no significant effect on viability $[161,162]$. A different in vitro study showed that acanthamoebic growth was inhibited by UVA without any added effect following the addition of riboflavin [163]. An animal study showed a partial response of Fusarium keratitis to CXL [164], while a similar protocol for Acanthamoeba showed no response and possible worsening following CXL [165].

In 2008, Iseli et al. [166] published the first clinical series describing the resolution of corneal ulcers complicated by melting in 5 patients failing to respond to antibiotic therapy. A prospective study evaluated the adjunct use of CXL for infectious keratitis in 40 eyes ( 24 bacterial, 7 fungal, 2 acanthamoebic and 7 with no positive cultures). Recording of the infiltrate area showed good response to treatment in cases of bacterial origin, but in fungal and acanthamoebic cases, a poor response was seen. Infiltrate depth and size were found to be important factors in treatment success. Deep infections may avoid the effect of CXL, which is performed through no more than $400 \mu \mathrm{m}$ of the anterior cornea [167]. In a different series of 16 patients with infective keratitis, the use of CXL as first-line treatment was evaluated. No antibiotics were given prior to CXL. In all eyes, the epithelium healed completely. Only 2 eyes required antibiotic treatment and 1 eye required an amniotic membrane transplant [168]. Smaller studies evaluated the use of CXL in cases of severe infectious keratitis that was refractory to antibiotics. In these studies (altogether 21 eyes in 3 studies), the majority of patients showed complete healing and scarring of the ulcer; the condition of 2 patients deteriorated: one required enucleation and the other a tectonic keratoplasty [169-171]. Fungal keratitis was evaluated clinically in an 8-patient series, where eyes with culture-proven fungal keratitis not responding to topical therapy were treated with CXL. All eyes showed complete healing of the ulcer following treatment [172].

Corneal melting caused by chemical burns may also respond to CXL. A study on rabbit corneas following alkali burn showed that 6 out of 10 control group corneas had melting after injury, with 2 corneas perforating, while in the CXL-treated group there was only 1 corneal melting (of 10 treated corneas) without any corneal perforation. A histological analysis also showed significantly less trauma in the CXL-treated group than in the control group [173]. 


\section{Bullous Keratopathy and Other Causes of Corneal Edema}

Failure of the endothelial pumping mechanism causes fluid accumulation in the extracellular space between the stromal lamellae [174]. CXL has been shown to increase the cornea's resistance to swelling $[110,175]$ and therefore was evaluated as a treatment for pseudophakic bullous keratopathy (PBK) and other causes of corneal edema. Edematous corneas treated with CXL demonstrated increased collagen fibril organization in the anterior stroma when compared with nontreated controls. This effect was less evident in corneas with advanced edema and/or fibrosis. The effect appeared to regress 3 months following CXL [176].

In 2008, Krueger et al. [177] described the results of an ex vivo study on 10 human eye bank corneas. Corneas treated with femtosecond laser-assisted pocket CXL showed improved clarity and a statistically significant improvement in corneal thickness. Nontreated controls showed no significant changes. This study also included a clinical case report where the use of CXL for PBK led to corneal thinning and a substantial improvement in visual acuity [177]. A combined clinicopathological study included 24 PBK patients treated with CXL. There was significant improvement in visual acuity, corneal thickness, pain score and corneal haze following CXL at 1 month postoperatively. However, all parameters had worsened by the 3-month postoperative examination [178].

\section{Combined CXL and Photorefractive Surgery}

The formation of ectasia following photorefractive surgery is currently one of its more serious postoperative complications $[25,142]$. In an effort to prevent postoperative ectasia and to increase corneal stabilization following photorefractive surgery, a method of performing simultaneous photorefractive surgery and CXL has been investigated. Factors increasing the risk of postrefractive ectasia include high myopic correction, thin corneas and a small residual bed thickness $[179,180]$. A study examining the effect of combined LASIK and CXL in patients with high myopia ( $\geq 6$ diopters) included 44 eyes. During a mean follow-up period of 3.5 years (range: $1-4.5$ years), none of the eyes developed ectasia despite their increased risk [181]. A comparative contralateral study included 34 hyperopic patients having combined LASIK and CXL in one eye and LASIK only in the fellow eye. Eyes undergoing combined LASIK and CXL demonstrated less regression of spherical equivalent during a 23-month mean follow-up period (statistically significant) [182]. The estimated incidence of PLE is up to $0.66 \%$ [25]. Therefore, studies on a much larger scale are required to properly evaluate whether the addition of CXL reduces the risk of postoperative ectasia. There are no studies evaluating the addition of CXL to PRK for the prophylaxis of ectasia following PRK.

\section{Corneal Wound Strengthening}

An ex vivo study on cadaveric human eyes showed that the addition of CXL to an ex vivo model of either penetrating or anterior lamellar keratoplasty led to an increase in adhesion strength of the donor-recipient corneal interface, evaluated using burst IOP and tissue separation force measurements [183].

\section{Safety}

Several safety issues following CXL have been addressed over the years.

\section{Corneal Infection}

Epithelial scraping performed routinely during CXL exposes the cornea to possible infections. Other factors theoretically increasing the risk of corneal infection are the use of a bandage soft contact lens and topical corticosteroids in the immediate postoperative period. There are no large-scale studies evaluating the rates of infection following CXL. There are, however, case reports in the literature of bacterial, polymicrobial, acanthamoebic and even herpetic keratitis following CXL procedures [61-65, 184]. The cases of herpetic keratitis described were in patients with no previously known herpetic infections [65, 184]. For this reason, topical antibiotics are routinely used following the procedure [47].

\section{Corneal Sensitivity and Tear Function}

Following CXL, corneal sensitivity has been shown to significantly decrease and gradually recover during the first 6 postoperative months $[185,186]$. No effect on tear secretion or tear film stability was observed [186].

\section{Effect on Limbal Epithelial Cells}

The integrity of limbal epithelial cells (LEC) is crucial for maintenance of a normal corneal epithelial structure. In vitro exposure of LEC to UVA levels similar to the levels used during CXL promoted expression of genes involved with apoptosis. The addition of riboflavin reduced the damage caused but did not prevent it completely [187]. The combination of riboflavin and UVA was also shown to inhibit the growth and expansion of LEC [188, 
189]. Enucleated human eyes undergoing a CXL procedure with half of the limbus protected by a metal shield showed a significant drop in viable LEC count and a lack of LEC growth in the area not protected by the metal shield [190]. Different results were shown for rabbit corneas, where exposure to CXL did not appear to cause any significant histological limbal changes [191]. There are no in vivo studies evaluating the effect of CXL on LEC. Therefore, the use of limbal protection during CXL should be considered. This is especially true for treatment of PMD, since the irradiated area in CXL for PMD may be decentered and thus positioned closer to the limbus [151].

\section{Stromal Haze and Sterile Infiltrates}

The formation of significant stromal haze following CXL is a potential complication that can affect visual acuity. A prospective series of 50 eyes, treated with CXL either for KCN or PLE, examined the degree of stromal haze both quantitatively and qualitatively throughout a 1 -year follow-up period. Stromal haze peaked 1 month after CXL, plateaued 3 months after CXL and decreased up to the 1-year follow-up point. At this point, stromal haze values returned to baseline in the PLE group but not in the KCN group [192]. A retrospective analysis of 163 eyes having undergone CXL showed the development of significant stromal haze in 14 of them (8.6\%), which persisted through the 1-year follow-up period. While the 149 eyes $(91.4 \%)$ that did not develop corneal haze showed significant improvement in visual acuity, the 14 eyes with corneal haze showed a significant deterioration in visual acuity. Preoperative corneal thickness was significantly reduced, and preoperative mean keratometry significantly increased, in the group of eyes developing haze when compared with those that did not. This may indicate that keratometry and corneal thickness may be factors predictive of the formation of stromal haze [193].

Few small patient series described the formation of sterile stromal infiltrates following CXL. In one series, 7 eyes developed peripheral sterile ring infiltrates, resolving completely following the instillation of topical steroids [194]. Another case series described the late formation of deep paracentral stromal infiltrates, persisting at 6 and 12 months following CXL. These did not cause a reduction in visual acuity due to their noncentral location [195]. Sterile infiltrates were also described as part of an inflammatory response after CXL - including keratitis, anterior chamber cells and keratic precipitates - appearing in 4 patients. These responded rapidly to topical and periocular steroids, with stromal opacity persisting in some of the eyes [196]. These infiltrates differ significantly from the previously described stromal haze, and probably do not represent the same pathologic process [194].

\section{Endothelial Toxicity and Thin Corneas}

The standard irradiance of $3 \mathrm{~mW} / \mathrm{cm}^{2}$ combined with the application of riboflavin $0.1 \%$ results in a significant and relatively sharp drop in UVA light of up to $95 \%$ and a resultant irradiance of the corneal endothelium (in a $500-\mu \mathrm{m}$-thick cornea) of only $0.15 \mathrm{~mW} / \mathrm{cm}^{2}(=0.27$ $\mathrm{J} / \mathrm{cm}^{2}$ ) [197]. Thus, it can be concluded that the endothelial cytotoxic threshold is far from being reached in eyes with sufficient corneal thickness. Wollensak et al. [198] published two studies in 2003, investigating the threshold dose and depth for endothelial toxicity in animal eyes. In rabbit corneas with a thickness of less than 400 $\mu \mathrm{m}$, the endothelial UVA dose crossed the cytotoxic threshold level of $0.65 \mathrm{~J} / \mathrm{cm}^{2}\left(0.36 \mathrm{~mW} / \mathrm{cm}^{2}\right)$ following the standard surface CXL UVA dose of $5.4 \mathrm{~J} / \mathrm{cm}^{2}(3 \mathrm{~mW} /$ $\mathrm{cm}^{2}$ ) [198]. In vitro analysis of porcine endothelial cells exposed to UVA and riboflavin showed similar results [199]. It was concluded that pachymetry should be routinely performed before CXL, and in corneas thinner than $400 \mu \mathrm{m}$, irradiation should not be performed, because of the cytotoxic risk to the endothelium [198, 199]. However, additional thinning of corneas thicker than $400 \mu \mathrm{m}$ can take place during the CXL procedure itself, causing them to become less than $400 \mu \mathrm{m}$ thick during the course of the procedure. A reduction in thickness of $75-87 \mu \mathrm{m}$ during different stages of the CXL procedure has been demonstrated $[200,201]$. This transient thinning can be related either to evaporation through the deepithelized surface or to the oncotic effect of $20 \%$ dextran used to form an isoosmolar riboflavin solution. This intraoperative thinning can theoretically increase the risk of endothelial damage even in corneas with apparently sufficient preoperative thickness. A retrospective analysis of 350 patients having undergone CXL found postoperative corneal edema in 10 of them (2.9\%). In 5 of the 10 patients, the corneal edema resolved, but in the remaining 5 patients edema change plateaued at 3 months after CXL and persisted. The patients were offered penetrating keratoplasty, with 2 of them undergoing this procedure. While it was not possible to conduct specular microscopy on those eyes, the mechanism suggested for persisting corneal edema was one of significant endothelial damage [202].

Several clinical studies examined the effect of CXL in thin corneas $(<400 \mu \mathrm{m})$. A clinical evaluation of 14 eyes with minimal corneal thickness $<400 \mu \mathrm{m}$ undergoing 
CXL using the Dresden protocol showed that 1 year following the procedure a significant endothelial decrease in cell density was present. While the procedure appeared effective, it resulted in significant endothelial damage [203]. The use of epi-on CXL in thin KCN corneas appeared to cause no endothelial changes postoperatively, but showed only moderate efficacy [204]. The use of hypoosmolar riboflavin solutions during CXL of thin corneas can increase intraoperative corneal thickness to safer levels. This has been evaluated clinically, showing an increase in intraoperative corneal thickness from $337 \mu \mathrm{m}$ preoperatively to $452 \mu \mathrm{m}$ intraoperatively. KCN showed stabilization following the procedure. However, endothelial cell integrity was not evaluated in this study [205]. A similar study of hypoosmolar riboflavin in CXL of thin corneas showed no apparent endothelial changes following the procedure [206]. The efficacy of hypoosmolar CXL seems to be reduced when compared with standard CXL [207]. A second problem with the use of hypoosmolar riboflavin is its short-term effect on corneal swelling, which was shown to last no more than 10-30 $\min$ [208].

\section{Corneal Drug Penetrance and IOP Measurements}

Corneal permeability has been shown to decrease in rabbit eyes following CXL both ex vivo as a reduction in mean permeability coefficient and in vivo as a reduction in pupillary response following instillation of pilocarpine drops [209]. A reduction in aqueous concentrations of ofloxacin and voriconazole following topical instillation was seen in CXL-treated eyes when compared with nonirradiated controls. This was shown in an ex vivo porcine model [210].

IOP measurements following CXL show overestimation, demonstrated using several tonometers including applanation tonometry (Goldmann), indentation/applanation tonometry (Tono-Pen; Reichert Technologies, Depew, N.Y., USA) and noncontact dynamic tonometry (ORA). This is attributed to the change in corneal biomechanics, leading to increased corneal rigidity. The difference in IOP measured following CXL ranged from 1.2 to $3.1 \mathrm{~mm} \mathrm{Hg}$, depending on the tonometer used $[211,212]$.

\section{Changes in Corneal Thickness}

Corneal thickness shows a significant reduction during and shortly after CXL. In one study, corneal thickness decreased by a mean of $87 \mu \mathrm{m}$ during the first $60 \mathrm{~min}$ [201]. Corneal thinning gradually resolves over the first 6 months following CXL and by 1 year returns to baseline values $[213,214]$.

\section{Postoperative Pain}

The epithelial debridement performed routinely in CXL is associated with postoperative pain. A prospective study including $178 \mathrm{KCN}$ eyes undergoing CXL evaluated pain during the first 5 postoperative days. Pain was evaluated using documentation of the need for analgesia and patients' subjective evaluation on the Wong-Baker FACES Pain Rating Scale. It was concluded that pain following CXL can be intense, especially in the first 3 days, even with an aggressive pain control regimen. All pain evaluation parameters decreased rapidly with each day following CXL. Pain was significantly correlated with the patient's age [66].

\section{Conclusion}

More than a decade after being introduced, collagen CXL is still changing. Indications are evolving, and different protocols are being developed and tested. Collagen CXL has changed the clinical approach to keratoectatic disorders dramatically. To the defensive approach - aiming to maximally improve current vision by different modalities (eye glasses, contact lenses and, finally, surgery) - the ophthalmologist adds an offensive approach, changing the course of the disease and preventing further loss of vision and functionality.

It is now understood that this modality is safe and effective. Future studies will lead to a better understanding of the risks and benefits. With this new experience, eventually the present relative disorder will probably be distilled down to a few treatment variants or protocols, appropriate for an exact list of rigid indications.

\section{Disclosure Statement}

None.

References

1 Dupps WJ Jr, Wilson SE: Biomechanics and wound healing in the cornea. Exp Eye Res 2006;83:709-720.

2 Maurice DM: The structure and transparency of the cornea. J Physiol 1957;136:263-286.

3 Komai Y, Ushiki T: The three-dimensional organization of collagen fibrils in the human cornea and sclera. Invest Ophthalmol Vis Sci 1991;32:2244-2258.

4 Meek KM, Fullwood NJ: Corneal and scleral collagens: a microscopist's perspective. Micron 2001;32:261-272.
Sorkin/Varssano 
5 Abahussin M, Hayes S, Knox Cartwright NE, 21 Gefen A, Shalom R, Elad D, Mandel Y: BioKamma-Lorger CS, Khan Y, Marshall J, Meek KM: 3D collagen orientation study of the human cornea using X-ray diffraction and femtosecond laser technology. Invest Ophthalmol Vis Sci 2009;50:5159-5164.

6 Hodson S, O'Leary D, Watkins S: The measurement of ox corneal swelling pressure by osmometry. J Physiol 1991;434:399-408.

7 Otori T: Electrolyte content of the rabbit corneal stroma. Exp Eye Res 1967;6:356-367.

8 Meek KM, Quantock AJ: The use of X-ray scattering techniques to determine corneal ultrastructure. Prog Retin Eye Res 2001;20:95137.

$>9$ Ruberti JW, Klyce SD: Physiological system models of the cornea; in Hung GK, Ciuffreda KJ (eds): Models of the Visual System. New York, Kluwer Academic/Plenum, 2001, pp 3-55.

10 Luce DA: Determining in vivo biomechanical properties of the cornea with an ocular response analyzer. J Cataract Refract Surg 2005; 31:156-162.

-11 Ortiz D, Pinero D, Shabayek MH, ArnalichMontiel F, Alio JL: Corneal biomechanical properties in normal, post-laser in situ keratomileusis, and keratoconic eyes. J Cataract Refract Surg 2007;33:1371-1375.

12 Ruberti JW, Roy AS, Roberts CJ: Corneal biomechanics and biomaterials. Annu Rev Biomed Eng 2011;13:269-295.

-13 Elsheikh A, Wang D, Brown M, Rama P, Campanelli M, Pye D: Assessment of corneal biomechanical properties and their variation with age. Curr Eye Res 2007;32:11-19.

14 Kamiya K, Shimizu K, Ohmoto F: Effect of aging on corneal biomechanical parameters using the Ocular Response Analyzer. J Refract Surg 2009;25:888-893.

15 Rabinowitz YS: Keratoconus. Surv Ophthalmol 1998;42:297-319.

16 Daxer A, Fratzl P: Collagen fibril orientation in the human corneal stroma and its implication in keratoconus. Invest Ophthalmol Vis Sci 1997;38:121-129.

17 Kohlhaas M, Spoerl E, Schilde T, Unger G, Wittig C, Pillunat LE: Biomechanical evidence of the distribution of cross-links in corneas treated with riboflavin and ultraviolet $\mathrm{A}$ light. J Cataract Refract Surg 2006;32:279283.

$\downarrow_{18}$ Bureau J, Pouliquen Y, Lorans G: Fibrocyte reaction to interleukin 1 stimulation in keratoconus (in German). [Original title: Fibrocyte response to interleukin 1 stimulation in keratoconus.] Klin Monbl Augenheilkd 1993; 203:269-274.

19 Dudakova L, Liskova P, Trojek T, Palos M, Kalasova S, Jirsova K: Changes in lysyl oxidase (LOX) distribution and its decreased activity in keratoconus corneas. Exp Eye Res 2012; 104:74-81.

20 Andreassen TT, Simonsen AH, Oxlund H: Biomechanical properties of keratoconus and normal corneas. Exp Eye Res 1980;31:435441. mechanical analysis of the keratoconic cornea. J Mech Behav Biomed Mater 2009;2:224236.

22 Shah S, Laiquzzaman M, Bhojwani R, Mantry S, Cunliffe I: Assessment of the biomechanical properties of the cornea with the Ocular Response Analyzer in normal and keratoconic eyes. Invest Ophthalmol Vis Sci 2007;48: 3026-3031. sogianni A, Kozobolis V: Evaluation of corneal hysteresis and corneal resistance factor after corneal cross-linking for keratoconus. Graefes Arch Clin Exp Ophthalmol 2012;250: 565-573.

24 Fontes BM, Ambrosio R Jr, Velarde GC, Nose $\mathrm{W}$ : Ocular response analyzer measurements in keratoconus with normal central corneal thickness compared with matched normal control eyes. J Refract Surg 2011;27:209-215.

25 Pallikaris IG, Kymionis GD, Astyrakakis NI: Corneal ectasia induced by laser in situ keratomileusis. J Cataract Refract Surg 2001;27: 1796-1802.

26 Geggel HS, Talley AR: Delayed onset keratectasia following laser in situ keratomileusis. J Cataract Refract Surg 1999;25:582-586.

27 Rao SN, Epstein RJ: Early onset ectasia following laser in situ keratomileusus [sic!]: case report and literature review. J Refract Surg 2002; 18:177-184.

$28 \mathrm{Kim} \mathrm{H}$, Song IK, Joo CK: Keratectasia after laser in situ keratomileusis: clinicopathological case report. Ophthalmologica 2006;220: 58-64. C, Talamo J, Edelhauser HF, Grossniklaus HE: Histopathological analysis of post-laserassisted in situ keratomileusis corneal ectasia with intrastromal corneal ring segments. Arch Ophthalmol 2005;123:1604-1607.

30 Baek T, Lee K, Kagaya F, Tomidokoro A, Amano S, Oshika T: Factors affecting the forward shift of posterior corneal surface after laser in situ keratomileusis. Ophthalmology 2001;108:317-320.

31 Wang Z, Chen J, Yang B: Posterior corneal surface topographic changes after laser in situ keratomileusis are related to residual corneal bed thickness. Ophthalmology 1999; 106:406409, discussion 409-410.

32 Dupps WJ Jr, Roberts C: Effect of acute biomechanical changes on corneal curvature after photokeratectomy. J Refract Surg 2001;17: 658-669.

33 Guirao A: Theoretical elastic response of the cornea to refractive surgery: risk factors for keratectasia. J Refract Surg 2005;21:176-185.

34 Akhtar S, Kirat O, Alkatan H, Shu X, Almubrad T: Ultrastructural features of corneas with pellucid marginal degeneration. Microsc Res Tech 2013;76:404-411.

35 Jenkins AD, Kratochvil P, Stepto RFT, Suter UW: Glossary of basic terms in polymer science. Pure Appl Chem 1996;68:2287-2311.
23 Gkika M, Labiris G, Giarmoukakis A, Kout-

29 Spirn MJ, Dawson DG, Rubinfeld RS, Burris
36 Wollensak G, Spörl E, Seiler T: Treatment of keratoconus by collagen cross linking (in German). Ophthalmologe 2003;100:44-49.

- 37 Sung HW, Chang WH, Ma CY, Lee MH: Crosslinking of biological tissues using genipin and/or carbodiimide. J Biomed Mater Res A 2003;64:427-438.

38 Hettlich HJ, Lucke K, Kreiner CF: Light-induced endocapsular polymerization of injectable lens refilling materials. Ger J Ophthalmol 1992;1:346-349.

39 Wollensak G: Crosslinking treatment of progressive keratoconus: new hope. Curr Opin Ophthalmol 2006;17:356-360.

40 Kamaev P, Friedman MD, Sherr E, Muller D: Photochemical kinetics of corneal cross-linking with riboflavin. Invest Ophthalmol Vis Sci 2012;53:2360-2367.

41 Pacifici RE, Davies KJ: Protein degradation as an index of oxidative stress. Methods Enzymol 1990;186:485-502.

42 Khadem J, Truong T, Ernest JT: Photodynamic biologic tissue glue. Cornea 1994;13: 406-410.

43 Goins KM, Khadem J, Majmudar PA, Ernest JT: Photodynamic biologic tissue glue to enhance corneal wound healing after radial keratotomy. J Cataract Refract Surg 1997;23: 1331-1338.

44 Siegel RC, Pinnell SR, Martin GR: Cross-linking of collagen and elastin: properties of lysyl oxidase. Biochemistry 1970;9:4486-4492.

45 Siegel RC: Biosynthesis of collagen crosslinks: increased activity of purified lysyl oxidase with reconstituted collagen fibrils. Proc Natl Acad Sci USA 1974;71:4826-4830.

46 Spoerl E, Huhle M, Seiler T: Induction of cross-links in corneal tissue. Exp Eye Res 1998;66:97-103.

47 Wollensak G, Spoerl E, Seiler T: Riboflavin/ ultraviolet-A-induced collagen crosslinking for the treatment of keratoconus. Am J Ophthalmol 2003;135:620-627.

48 Schumacher S, Oeftiger L, Mrochen M: Equivalence of biomechanical changes induced by rapid and standard corneal crosslinking, using riboflavin and ultraviolet radiation. Invest Ophthalmol Vis Sci 2011;52: 9048-9052.

49 Wernli J, Schumacher S, Spoerl E, Mrochen M: The efficacy of corneal cross-linking shows a sudden decrease with very high intensity UV light and short treatment time. Invest Ophthalmol Vis Sci 2013;54:1176-1180.

50 Rocha KM, Ramos-Esteban JC, Qian Y, Herekar S, Krueger RR: Comparative study of riboflavin-UVA cross-linking and 'flash-linking' using surface wave elastometry. J Refract Surg 2008;24:S748-S751.

51 Beshtawi IM, Akhtar R, Hillarby MC, O'Donnell C, Zhao X, Brahma A, Carley F, Derby B, Radhakrishnan H: Biomechanical properties of human corneas following lowand high-intensity collagen cross-linking determined with scanning acoustic microscopy. Invest Ophthalmol Vis Sci 2013;54:52735280 . 
52 Cingü AK, Sogutlu-Sari E, Cinar Y, Sahin M, Türkcü FM, Yüksel H, Sahin A, Caca I: Transient corneal endothelial changes following accelerated collagen cross-linking for the treatment of progressive keratoconus. Cutan Ocul Toxicol 2013, Epub ahead of print.

53 Kanellopoulos AJ: Long term results of a prospective randomized bilateral eye comparison trial of higher fluence, shorter duration ultraviolet A radiation, and riboflavin collagen cross linking for progressive keratoconus. Clin Ophthalmol 2012;6:97-101.

-54 Cinar Y, Cingü AK, Türkcü FM, Yüksel H, Sahin A, Yildirim A, Caca I, Cinar T: Accelerated corneal collagen cross-linking for progressive keratoconus. Cutan Ocul Toxicol 2013, Epub ahead of print.

55 Mazzotta C, Baiocchi S, Denaro R, Tosi GM, Caporossi T: Corneal collagen cross-linking to stop corneal ectasia exacerbated by radial keratotomy. Cornea 2011;30:225-228.

-56 Caporossi A, Mazzotta C, Baiocchi S, Caporossi T, Denaro R: Age-related longterm functional results after riboflavin UV A corneal cross-linking. J Ophthalmol 2011; 2011:608041.

57 Arbelaez MC: ICRS implantation plus LASEK 7 and accelerated CXL. Cataract and Refractive Surgery Today, April 2013, pp 32-33.

58 Famose F: Evaluation of accelerated collagen cross-linking for the treatment of melting keratitis in ten cats. Vet Ophthalmol 2013, Epub ahead of print.

-59 Bottos KM, Schor P, Dreyfuss JL, Nader HB, Chamon W: Effect of corneal epithelium on ultraviolet-A and riboflavin absorption. Arq Bras Oftalmol 2011;74:348-351.

60 Baiocchi S, Mazzotta C, Cerretani D, Caporossi T, Caporossi A: Corneal crosslinking: riboflavin concentration in corneal stroma exposed with and without epithelium. J Cataract Refract Surg 2009;35:893-899.

-61 Perez-Santonja JJ, Artola A, Javaloy J, Alio JL, Abad JL: Microbial keratitis after corneal collagen crosslinking. J Cataract Refract Surg 2009;35:1138-1140.

62 Pollhammer M, Cursiefen C: Bacterial keratitis early after corneal crosslinking with riboflavin and ultraviolet-A. J Cataract Refract Surg 2009;35:588-589.

63 Rama P, di Matteo F, Matuska S, Paganoni G, Spinelli A: Acanthamoeba keratitis with perforation after corneal crosslinking and bandage contact lens use. J Cataract Refract Surg 2009;35:788-791.

-64 Zamora KV, Males JJ: Polymicrobial keratitis after a collagen cross-linking procedure with postoperative use of a contact lens: a case report. Cornea 2009;28:474-476.

65 Kymionis GD, Portaliou DM, Bouzoukis DI, Suh LH, Pallikaris AI, Markomanolakis M, Yoo SH: Herpetic keratitis with iritis after corneal crosslinking with riboflavin and ultraviolet A for keratoconus. J Cataract Refract Surg 2007;33:1982-1984.
66 Ghanem VC, Ghanem RC, de Oliveira R: Postoperative pain after corneal collagen cross-linking. Cornea 2013;32:20-24.

-67 Scarcelli G, Kling S, Quijano E, Pineda R, Marcos S, Yun SH: Brillouin microscopy of collagen crosslinking: noncontact depth-dependent analysis of corneal elastic modulus. Invest Ophthalmol Vis Sci 2013;54:14181425 .

68 Tao X, Yu H, Zhang Y, Li Z, Jhanji V, Ni S, Wang Y, Mu G: Role of corneal epithelium in riboflavin/ultraviolet-A mediated corneal cross-linking treatment in rabbit eyes. Biomed Res Int 2013;2013:624563.

69 Wollensak G, Iomdina E: Biomechanical and histological changes after corneal crosslinking with and without epithelial debridement. J Cataract Refract Surg 2009;35:540-546.

70 Mastropasqua L, Nubile M, Lanzini M, Calienno R, Mastropasqua R, Agnifili L, Toto L: Morphological modification of the cornea after standard and transepithelial corneal crosslinking as imaged by anterior segment optical coherence tomography and laser scanning in vivo confocal microscopy. Cornea 2013;32: 855-861.

1 Malhotra C, Shetty R, Kumar RS, Veluri H, Nagaraj H, Shetty KB: In vivo imaging of riboflavin penetration during collagen crosslinking with hand-held spectral domain optical coherence tomography. J Refract Surg 2012;28:776-780.

72 Filippello M, Stagni E, O’Brart D: Transepithelial corneal collagen crosslinking: bilateral study. J Cataract Refract Surg 2012;38:283291.

73 Caporossi A, Mazzotta C, Paradiso AL, Baiocchi S, Marigliani D, Caporossi T: Transepithelial corneal collagen crosslinking for progressive keratoconus: 24-month clinical results. J Cataract Refract Surg 2013;39:1157-1163.

74 Raiskup F, Pinelli R, Spoerl E: Riboflavin osmolar modification for transepithelial corneal cross-linking. Curr Eye Res 2012;37:234-238.

75 Kissner A, Spoerl E, Jung R, Spekl K, Pillunat LE, Raiskup F: Pharmacological modification of the epithelial permeability by benzalkonium chloride in UVA/riboflavin corneal collagen cross-linking. Curr Eye Res 2010;35: 715-721.

76 Leccisotti A, Islam T: Transepithelial corneal collagen cross-linking in keratoconus. J Refract Surg 2010;26:942-948.

77 Koppen C, Wouters K, Mathysen D, Rozema J, Tassignon MJ: Refractive and topographic results of benzalkonium chloride-assisted transepithelial crosslinking. J Cataract Refract Surg 2012;38:1000-1005.

78 Vinciguerra P, Rechichi M, Rosetta P, Romano MR, Mastropasqua L, Scorcia V, Azzolini C, Vinciguerra R: High fluence iontophoretic corneal collagen cross-linking: in vivo OCT imaging of riboflavin penetration. J Refract Surg 2013;29:376-377.

79 Bikbova G, Bikbov M: Transepithelial corneal collagen cross-linking by iontophoresis of riboflavin. Acta Ophthalmol 2014;92:e30-e34.
80 Lamy R, Chan E, Zhang H, Salgaonkar VA, Good SD, Porco TC, Diederich CJ, Stewart JM: Ultrasound-enhanced penetration of topical riboflavin into the corneal stroma. Invest Ophthalmol Vis Sci 2013;54:5908-5912.

-81 Bottos KM, Oliveira AG, Bersanetti PA, Nogueira RF, Lima-Filho AA, Cardillo JA, Schor P, Chamon W: Corneal absorption of a new riboflavin-nanostructured system for transepithelial collagen cross-linking. PLoS One 2013;8:e66408.

82 Salman AG: Transepithelial corneal collagen crosslinking for progressive keratoconus in a pediatric age group. J Cataract Refract Surg 2013;39:1164-1170.

83 Magli A, Forte R, Tortori A, Capasso L, Marsico G, Piozzi E: Epithelium-off corneal collagen cross-linking versus transepithelial cross-linking for pediatric keratoconus. Cornea 2013;32:597-601.

84 Buzzonetti L, Petrocelli G: Transepithelial corneal cross-linking in pediatric patients: early results. J Refract Surg 2012;28:763-767.

85 Marcovich AL, Brandis A, Daphna O, Feine I, Pinkas I, Goldschmidt R, Kalchenko V, Berkutzki T, Wagner HD, Salomon Y, Scherz A: Stiffening of rabbit corneas by the bacteriochlorophyll derivative WST11 using near infrared light. Invest Ophthalmol Vis Sci 2012; 53:6378-6388.

- 86 Cherfan D, Verter EE, Melki S, Gisel TE, Doyle FJ Jr, Scarcelli G, Yun SH, Redmond RW, Kochevar IE: Collagen cross-linking using rose bengal and green light to increase corneal stiffness. Invest Ophthalmol Vis Sci 2013;54:3426-3433.

87 Chai D, Juhasz T, Brown DJ, Jester JV: Nonlinear optical collagen cross-linking and mechanical stiffening: a possible photodynamic therapeutic approach to treating corneal ectasia. J Biomed Opt 2013;18:038003.

88 Heck HD, Casanova M, Starr TB: Formaldehyde toxicity: new understanding. Crit Rev Toxicol 1990;20:397-426.

89 Avila MY, Gerena VA, Navia JL: Corneal crosslinking with genipin, comparison with UV-riboflavin in ex-vivo model. Mol Vis 2012;18:1068-1073.

90 Paik DC, Solomon MR, Wen Q, Turro NJ Trokel SL: Aliphatic $\beta$-nitroalcohols for therapeutic corneoscleral cross-linking: chemical mechanisms and higher order nitroalcohols. Invest Ophthalmol Vis Sci 2010;51:836-843.

91 Li X, Li Y, Rao Y, Solomon MR, Paik DC, Turro NJ: Mechanistic and catalytic studies of $\beta$-nitroalcohol crosslinking with polyamine. J Appl Polym Sci 2013;128:3696-3701.

92 Bollmeier AF: Nitroalcohols; in Kirk RE, Othmer DF, Kroschwitz JI, Howe-Grant M (eds): Encyclopedia of Chemical Technology. New York, John Wiley \& Sons, 1996.

93 Seiler T, Hafezi F: Corneal cross-linkinginduced stromal demarcation line. Cornea 2006;25:1057-1059.

Sorkin/Varssano 
94 Hayes S, Kamma-Lorger CS, Boote C, Young RD, Quantock AJ, Rost A, Khatib Y, Harris J, Yagi N, Terrill N, Meek KM: The effect of riboflavin/UVA collagen cross-linking therapy on the structure and hydrodynamic behaviour of the ungulate and rabbit corneal stroma. PLoS One 2013;8:e52860.

95 Bueno JM, Gualda EJ, Giakoumaki A, PerezMerino P, Marcos S, Artal P: Multiphoton microscopy of ex vivo corneas after collagen cross-linking. Invest Ophthalmol Vis Sci 2011;52:5325-5331.

96 Wollensak G, Herbst H: Significance of the lacunar hydration pattern after corneal cross linking. Cornea 2010;29:899-903.

-97 Messmer EM, Meyer P, Herwig MC, Loeffler KU, Schirra F, Seitz B, Thiel M, Reinhard T, Kampik A, Auw-Haedrich C: Morphological and immunohistochemical changes after corneal cross-linking. Cornea 2013;32:111117.

98 Croxatto JO, Tytiun AE, Argento CJ: Sequential in vivo confocal microscopy study of corneal wound healing after cross-linking in patients with keratoconus. J Refract Surg 2010;26:638-645.

-99 Mazzotta C, Caporossi T, Denaro R, Bovone C, Sparano C, Paradiso A, Baiocchi S, Caporossi A: Morphological and functional correlations in riboflavin UV A corneal collagen cross-linking for keratoconus. Acta Ophthalmol 2012;90:259-265.

-100 Akhtar S, Almubrad T, Paladini I, Mencucci R: Keratoconus corneal architecture after riboflavin/ultraviolet A cross-linking: ultrastructural studies. Mol Vis 2013;19:15261537.

101 Wollensak G, Wilsch M, Spoerl E, Seiler T: Collagen fiber diameter in the rabbit cornea after collagen crosslinking by riboflavin/ UVA. Cornea 2004;23:503-507.

102 Koller T, Pajic B, Vinciguerra P, Seiler T: Flattening of the cornea after collagen crosslinking for keratoconus. J Cataract Refract Surg 2011;37:1488-1492.

-103 Kling S, Remon L, Perez-Escudero A, Merayo-Lloves J, Marcos S: Corneal biomechanical changes after collagen cross-linking from porcine eye inflation experiments. Invest Ophthalmol Vis Sci 2010;51:39613968.

104 Wollensak G, Iomdina E: Long-term biomechanical properties of rabbit cornea after photodynamic collagen crosslinking. Acta Ophthalmol 2009;87:48-51.

105 Wollensak G, Spoerl E, Seiler T: Stress-strain measurements of human and porcine corneas after riboflavin-ultraviolet-A-induced cross-linking. J Cataract Refract Surg 2003; 29:1780-1785.

106 Knox Cartwright NE, Tyrer JR, Marshall J: In vitro quantification of the stiffening effect of corneal cross-linking in the human cornea using radial shearing speckle pattern interferometry. J Refract Surg 2012;28:503508.
107 Greenstein SA, Fry KL, Hersh PS: In vivo biomechanical changes after corneal collagen cross-linking for keratoconus and corneal ectasia: 1 -year analysis of a randomized, controlled, clinical trial. Cornea 2012;31: 21-25.

108 Sedaghat M, Naderi M, Zarei-Ghanavati M: Biomechanical parameters of the cornea after collagen crosslinking measured by waveform analysis. J Cataract Refract Surg 2010; 36:1728-1731.

109 Spoerl E, Wollensak G, Seiler T: Increased resistance of crosslinked cornea against enzymatic digestion. Curr Eye Res 2004;29: 35-40.

110 Wollensak G, Aurich H, Pham DT, Wirbelauer C: Hydration behavior of porcine cornea crosslinked with riboflavin and ultraviolet A. J Cataract Refract Surg 2007;33:516521.

111 Wittig-Silva C, Whiting M, Lamoureux E, Lindsay RG, Sullivan LJ, Snibson GR: A randomized controlled trial of corneal collagen cross-linking in progressive keratoconus: preliminary results. J Refract Surg 2008; 24:S720-S725.

112 Viswanathan D, Males J: Prospective longitudinal study of corneal collagen cross-linking in progressive keratoconus. Clin Experiment Ophthalmol 2013;41:531-536.

113 Hersh PS, Greenstein SA, Fry KL: Corneal collagen crosslinking for keratoconus and corneal ectasia: one-year results. J Cataract Refract Surg 2011;37:149-160.

114 Lamy R, Netto CF, Reis RG, Procopio B, Porco TC, Stewart JM, Dantas AM, Moraes HV Jr: Effects of corneal cross-linking on contrast sensitivity, visual acuity, and corneal topography in patients with keratoconus. Cornea 2013;32:591-596.

115 Agrawal VB: Corneal collagen cross-linking with riboflavin and ultraviolet-A light for keratoconus: results in Indian eyes. Indian J Ophthalmol 2009;57:111-114.

116 Coskunseven E, Jankov MR 2nd, Hafezi F: Contralateral eye study of corneal collagen cross-linking with riboflavin and UVA irradiation in patients with keratoconus. J Refract Surg 2009;25:371-376.

117 Guber I, Guber J, Kaufmann C, Bachmann LM, Thiel MA: Visual recovery after corneal crosslinking for keratoconus: a 1-year follow-up study. Graefes Arch Clin Exp Ophthalmol 2013;251:803-807.

-118 Vinciguerra P, Albe E, Trazza S, Seiler T, Epstein D: Intraoperative and postoperative effects of corneal collagen cross-linking on progressive keratoconus. Arch Ophthalmol 2009;127:1258-1265.

119 Arbelaez MC, Sekito MB, Vidal C, Choudhury SR: Collagen cross-linking with riboflavin and ultraviolet-A light in keratoconus: one-year results. Oman J Ophthalmol 2009; 2:33-38.

120 El-Raggal TM: Riboflavin-ultraviolet A corneal cross-linking for keratoconus. Middle East Afr J Ophthalmol 2009;16:256-259.
121 Goldich Y, Marcovich AL, Barkana Y, Mandel Y, Hirsh A, Morad Y, Avni I, Zadok D: Clinical and corneal biomechanical changes after collagen cross-linking with riboflavin and UV irradiation in patients with progressive keratoconus: results after 2 years of follow-up. Cornea 2012;31:609-614.

122 Henriquez MA, Izquierdo L Jr, Bernilla C, Zakrzewski PA, Mannis M: Riboflavin/ultraviolet A corneal collagen cross-linking for the treatment of keratoconus: visual outcomes and Scheimpflug analysis. Cornea 2011;30:281-286.

123 Caporossi A, Mazzotta C, Baiocchi S, Caporossi T: Long-term results of riboflavin ultraviolet A corneal collagen cross-linking for keratoconus in Italy: the Siena Eye Cross Study. Am J Ophthalmol 2010;149:585-593.

124 Hashemi H, Seyedian MA, Miraftab M, Fotouhi A, Asgari S: Corneal collagen crosslinking with riboflavin and ultraviolet $\mathrm{A}$ irradiation for keratoconus: long-term results. Ophthalmology 2013;120:1515-1520.

125 Poli M, Cornut PL, Balmitgere T, Aptel F, Janin H, Burillon C: Prospective study of corneal collagen cross-linking efficacy and tolerance in the treatment of keratoconus and corneal ectasia: 3-year results. Cornea 2013;32:583-590.

126 Raiskup-Wolf F, Hoyer A, Spoerl E, Pillunat LE: Collagen crosslinking with riboflavin and ultraviolet-A light in keratoconus: longterm results. J Cataract Refract Surg 2008;34: 796-801.

127 Vinciguerra R, Romano MR, Camesasca FI, Azzolini C, Trazza S, Morenghi E, Vinciguerra P: Corneal cross-linking as a treatment for keratoconus: four-year morphologic and clinical outcomes with respect to patient age. Ophthalmology 2013;120:908916.

128 Kanellopoulos AJ: Comparison of sequential vs same-day simultaneous collagen cross-linking and topography-guided PRK for treatment of keratoconus. J Refract Surg 2009;25:S812-S818.

129 Kymionis GD, Portaliou DM, Kounis GA, Limnopoulou AN, Kontadakis GA, Grentzelos MA: Simultaneous topography-guided photorefractive keratectomy followed by corneal collagen cross-linking for keratoconus. Am J Ophthalmol 2011;152:748-755.

130 Tuwairqi WS, Sinjab MM: Safety and efficacy of simultaneous corneal collagen crosslinking with topography-guided PRK in managing low-grade keratoconus: 1-year follow-up. J Refract Surg 2012;28:341-345.

131 Kymionis GD, Kontadakis GA, Kounis GA, Portaliou DM, Karavitaki AE, Magarakis M, Yoo S, Pallikaris IG: Simultaneous topography-guided PRK followed by corneal collagen cross-linking for keratoconus. J Refract Surg 2009;25:S807-S811. 
132 Stojanovic A, Zhang J, Chen X, Nitter TA, Chen S, Wang Q: Topography-guided transepithelial surface ablation followed by corneal collagen cross-linking performed in a single combined procedure for the treatment of keratoconus and pellucid marginal degeneration. J Refract Surg 2010;26:145-152.

-133 Alessio G, L'Abbate M, Sborgia C, la Tegola MG: Photorefractive keratectomy followed by cross-linking versus cross-linking alone for management of progressive keratoconus: two-year follow-up. Am J Ophthalmol 2013; 155:54-65.e1.

134 Pinero DP, Alio JL, Barraquer RI, Michael R: Corneal biomechanical changes after intracorneal ring segment implantation in keratoconus. Cornea 2012;31:491-499.

-135 Legare ME, Iovieno A, Yeung SN, Lichtinger A, Kim P, Hollands S, Slomovic AR, Rootman DS: Intacs with or without same-day corneal collagen cross-linking to treat corneal ectasia. Can J Ophthalmol 2013;48: 173-178.

136 Renesto Ada C, Melo LA Jr, Sartori Mde F, Campos M: Sequential topical riboflavin with or without ultraviolet A radiation with delayed intracorneal ring segment insertion for keratoconus. Am J Ophthalmol 2012; 153:982-993.e3.

137 Reeves SW, Stinnett S, Adelman RA, Afshari NA: Risk factors for progression to penetrating keratoplasty in patients with keratoconus. Am J Ophthalmol 2005;140:607-611.

$\$ 138$ Caporossi A, Mazzotta C, Baiocchi S, Caporossi T, Denaro R, Balestrazzi A: Riboflavin-UVA-induced corneal collagen crosslinking in pediatric patients. Cornea 2012; $31: 227-231$

139 Vinciguerra P, Albe E, Frueh BE, Trazza S, Epstein D: Two-year corneal cross-linking results in patients younger than 18 years with documented progressive keratoconus. Am J Ophthalmol 2012;154:520-526.

140 Arora R, Gupta D, Goyal JL, Jain P: Results of corneal collagen cross-linking in pediatric patients. J Refract Surg 2012;28:759-762.

- 141 Labiris G, Giarmoukakis A, Sideroudi H, Kozobolis V: Impact of keratoconus, crosslinking and cross-linking combined with topography-guided photorefractive keratectomy on self-reported quality of life: a 3-year update. Cornea 2013;32:e186-e188.

142 Binder PS: Ectasia after laser in situ keratomileusis. J Cataract Refract Surg 2003;29: 2419-2429.

143 Kymionis GD, Diakonis VF, Kalyvianaki M, Portaliou D, Siganos C, Kozobolis VP, Pallikaris AI: One-year follow-up of corneal confocal microscopy after corneal crosslinking in patients with post laser in situ keratosmileusis [sic!] ectasia and keratoconus. Am J Ophthalmol 2009;147:774-778, 778.e1.

144 Hafezi F, Kanellopoulos J, Wiltfang R, Seiler $\mathrm{T}$ : Corneal collagen crosslinking with riboflavin and ultraviolet A to treat induced keratectasia after laser in situ keratomileusis. J Cataract Refract Surg 2007;33:2035-2040.
145 Vinciguerra P, Camesasca FI, Albe E, Trazza S: Corneal collagen cross-linking for ectasia after excimer laser refractive surgery: 1-year results. J Refract Surg 2010;26:486-497.

146 Salgado JP, Khoramnia R, Lohmann CP, Winkler von Mohrenfels C: Corneal collagen crosslinking in post-LASIK keratectasia. Br J Ophthalmol 2011;95:493-497.

147 Li G, Fan ZJ, Peng XJ: Corneal collagen crosslinking for corneal ectasia of postLASIK: one-year results. Int J Ophthalmol 2012;5:190-195.

148 Richoz O, Mavrakanas N, Pajic B, Hafezi F: Corneal collagen cross-linking for ectasia after LASIK and photorefractive keratectomy: long-term results. Ophthalmology 2013; 120:1354-1359.

149 Kanellopoulos AJ, Binder PS: Management of corneal ectasia after LASIK with combined, same-day, topography-guided partial transepithelial PRK and collagen cross-linking: the Athens protocol. J Refract Surg 2011; 27:323-331.

150 Robin JB, Schanzlin DJ, Verity SM, Barron BA, Arffa RC, Suarez E, Kaufman HE: Peripheral corneal disorders. Surv Ophthalmol 1986;31:1-36.

151 Koller T, Schumacher S, Fankhauser F 2nd, Seiler T: Riboflavin/ultraviolet A crosslinking of the paracentral cornea. Cornea 2013; 32:165-168.

152 Greenstein SA, Fry KL, Hersh PS: Effect of topographic cone location on outcomes of corneal collagen cross-linking for keratoconus and corneal ectasia. J Refract Surg 2012; 28:397-405.

153 Steppat MH, Raiskup-Wolf F, Spörl E, Hoyer A, Pillunat LE: Collagen cross linking in patients with pellucid marginal corneal degeneration (PMD) (poster presentation). ARVO 2008.

154 Kymionis GD, Grentzelos MA, Portaliou DM, Karavitaki AE, Krasia MS, Dranidis GK, Kozobolis VP: Photorefractive keratectomy followed by same-day corneal collagen crosslinking after intrastromal corneal ring segment implantation for pellucid marginal degeneration. J Cataract Refract Surg 2010; 36:1783-1785.

155 Hassan Z, Nemeth G, Modis L, Szalai E, Berta A: Collagen cross-linking in the treatment of pellucid marginal degeneration. Indian J Ophthalmol 2013, Epub ahead of print.

156 Spadea L: Corneal collagen cross-linking with riboflavin and UVA irradiation in pellucid marginal degeneration. J Refract Surg 2010;26:375-377.

157 Tsugita A, Okada Y, Uehara K: Photosensitized inactivation of ribonucleic acids in the presence of riboflavin. Biochim Biophys Acta 1965;103:360-363.

158 Kumar V, Lockerbie O, Keil SD, Ruane PH, Platz MS, Martin CB, Ravanat JL, Cadet J, Goodrich RP: Riboflavin and UV-light based pathogen reduction: extent and consequence of DNA damage at the molecular level. Photochem Photobiol 2004;80:15-21.
159 Schrier A, Greebel G, Attia H, Trokel S, Smith EF: In vitro antimicrobial efficacy of riboflavin and ultraviolet light on Staphylococcus aureus, methicillin-resistant Staphylococcus aureus, and Pseudomonas aeruginosa. J Refract Surg 2009;25:S799-S802.

160 Makdoumi K, Bäckman A, Mortensen J, Crafoord S: Evaluation of antibacterial efficacy of photo-activated riboflavin using ultraviolet light (UVA). Graefes Arch Clin Exp Ophthalmol 2010;248:207-212.

161 Kashiwabuchi RT, Carvalho FR, Khan YA, Hirai F, Campos MS, McDonnell PJ: Assessment of fungal viability after long-wave ultraviolet light irradiation combined with riboflavin administration. Graefes Arch Clin Exp Ophthalmol 2013;251:521-527.

162 del Buey MA, Cristobal JA, Casas P, Goni P, Clavel A, Minguez E, Lanchares E, Garcia A, Calvo B: Evaluation of in vitro efficacy of combined riboflavin and ultraviolet $\mathrm{A}$ for Acanthamoeba isolates. Am J Ophthalmol 2012;153:399-404.

163 Makdoumi K, Bäckman A, Mortensen J, Magnuson A, Crafoord S: Comparison of UVA- and UVA/riboflavin-induced growth inhibition of Acanthamoeba castellanii. Graefes Arch Clin Exp Ophthalmol 2013; 251:509-514.

164 Galperin G, Berra M, Tau J, Boscaro G, Zarate J, Berra A: Treatment of fungal keratitis from Fusarium infection by corneal crosslinking. Cornea 2012;31:176-180.

165 Berra M, Galperin G, Boscaro G, Zarate J, Tau J, Chiaradia P, Berra A: Treatment of Acanthamoeba keratitis by corneal crosslinking. Cornea 2013;32:174-178.

166 Iseli HP, Thiel MA, Hafezi F, Kampmeier J, Seiler T: Ultraviolet A/riboflavin corneal cross-linking for infectious keratitis associated with corneal melts. Cornea 2008;27: 590-594.

167 Price MO, Tenkman LR, Schrier A, Fairchild KM, Trokel SL, Price FW Jr: Photoactivated riboflavin treatment of infectious keratitis using collagen cross-linking technology. J Refract Surg 2012;28:706-713.

168 Makdoumi K, Mortensen J, Sorkhabi O, Malmvall BE, Crafoord S: UVA-riboflavin photochemical therapy of bacterial keratitis: a pilot study. Graefes Arch Clin Exp Ophthalmol 2012;250:95-102.

169 Sorkhabi R, Sedgipoor M, Mahdavifard A: Collagen cross-linking for resistant corneal ulcer. Int Ophthalmol 2013;33:61-66.

170 Panda A, Krishna SN, Kumar S: Photo-activated riboflavin therapy of refractory corneal ulcers. Cornea 2012;31:1210-1213.

-171 Rosetta P, Vinciguerra R, Romano MR, Vinciguerra P: Corneal collagen cross-linking window absorption. Cornea 2013;32:550554.

172 Li Z, Jhanji V, Tao X, Yu H, Chen W, Mu G: Riboflavin/ultraviolet light-mediated crosslinking for fungal keratitis. Br J Ophthalmol 2013;97:669-671. 
173 Gao XW, Zhao XD, Li WJ, Zhou X, Liu Y: Experimental study on the treatment of rabbit corneal melting after alkali burn with collagen cross-linking. Int J Ophthalmol 2012; 5:147-150.

174 Feiz V: Corneal edema; in Krachmer JH, Mannis ML, Holland EJ (eds): Cornea. Philadelphia, Mosby Elsevier, 2011, pp 283-288.

175 Søndergaard AP, Ivarsen A, Hjortdal J: Reduction of stromal swelling pressure after UVA-riboflavin cross-linking. Invest Ophthalmol Vis Sci 2013;54:1625-1634.

-176 Bottos KM, Hofling-Lima AL, Barbosa MC, Barbosa JB Jr, Dreyfuss JL, Schor P, Nader HB: Effect of collagen cross-linking in stromal fibril organization in edematous human corneas. Cornea 2010;29:789-793.

-177 Krueger RR, Ramos-Esteban JC, Kanellopoulos AJ: Staged intrastromal delivery of riboflavin with UVA cross-linking in advanced bullous keratopathy: laboratory investigation and first clinical case. J Refract Surg 2008;24:S730-S736.

178 Arora R, Manudhane A, Saran RK, Goyal J, Goyal G, Gupta D: Role of corneal collagen cross-linking in pseudophakic bullous keratopathy: a clinicopathological study. Ophthalmology 2013;120:2413-2418.

-179 Randleman JB, Woodward M, Lynn MJ, Stulting RD: Risk assessment for ectasia after corneal refractive surgery. Ophthalmology 2008;115:37-50.

180 Randleman JB, Trattler WB, Stulting RD: Validation of the Ectasia Risk Score System for preoperative laser in situ keratomileusis screening. Am J Ophthalmol 2008;145:813818.

181 Kanellopoulos AJ: Long-term safety and efficacy follow-up of prophylactic higher fluence collagen cross-linking in high myopic laser-assisted in situ keratomileusis. Clin Ophthalmol 2012;6:1125-1130.

182 Kanellopoulos AJ, Kahn J: Topographyguided hyperopic LASIK with and without high irradiance collagen cross-linking: initial comparative clinical findings in a contralateral eye study of 34 consecutive patients. J Refract Surg 2012;28:S837-S840.

183 Rocha G, Butler M, Butler A, Hackett JM: Femtosecond-UVA-riboflavin (FUR) crosslinking approach to penetrating keratoplasty and anterior lamellar keratoplasty. Saudi J Ophthalmol 2011;25:261-267.

184 Yüksel N, Bilgihan K, Hondur AM: Herpetic keratitis after corneal collagen cross-linking with riboflavin and ultraviolet-A for progressive keratoconus. Int Ophthalmol 2011; 31:513-515.

185 Wasilewski D, Mello GH, Moreira H: Impact of collagen crosslinking on corneal sensitivity in keratoconus patients. Cornea 2013;32:899-902.

-186 Kontadakis GA, Kymionis GD, Kankariya VP, Pallikaris AI: Effect of corneal collagen crosslinking on corneal innervation, corneal sensitivity, and tear function of patients with keratoconus. Ophthalmology 2013;120:917-922.
87 Matalia H, Shetty R, Dhamodaran K, Subramani M, Arokiaraj V, Das D: Potential apoptotic effect of ultraviolet-A irradiation during cross-linking: a study on ex vivo cultivated limbal epithelial cells. Br J Ophthalmol 2012;96:1339-1345.

188 Thorsrud A, Nicolaissen B, Drolsum L: Corneal collagen crosslinking in vitro: inhibited regeneration of human limbal epithelial cells after riboflavin-ultraviolet-A exposure. J Cataract Refract Surg 2012;38:1072-1076.

189 Jeyalatha V, Jambulingam M, Gupta N, Padmanabhan P, Madhavan HN: Study on polymethylmethacrylate ring in protecting limbal stem cells during collagen cross-linking. Ophthalmic Res 2013;50:113-116.

190 Vimalin J, Gupta N, Jambulingam M, Padmanabhan P, Madhavan HN: The effect of riboflavin-UV-A treatment on corneal limbal epithelial cells: a study on human cadaver eyes. Cornea 2012;31:1052-1059.

191 Wollensak G, Mazzotta C, Kalinski T, Sel S: Limbal and conjunctival epithelium after corneal cross-linking using riboflavin and UVA. Cornea 2011;30:1448-1454.

192 Greenstein SA, Fry KL, Bhatt J, Hersh PS: Natural history of corneal haze after collagen crosslinking for keratoconus and corneal ectasia: Scheimpflug and biomicroscopic analysis. J Cataract Refract Surg 2010; 36:2105-2114.

193 Raiskup F, Hoyer A, Spoerl E: Permanent corneal haze after riboflavin-UVA-induced cross-linking in keratoconus. J Refract Surg 2009;25:S824-S828.

194 Ghanem RC, Netto MV, Ghanem VC, Santhiago MR, Wilson SE: Peripheral sterile corneal ring infiltrate after riboflavin-UVA collagen cross-linking in keratoconus. Cornea 2012;31:702-705

195 Kato N, Konomi K, Saiki M, Negishi K, Takeuchi M, Shimazaki J, Tsubota K: Deep stromal opacity after corneal cross-linking. Cornea 2013;32:895-898.

196 Koppen C, Vryghem JC, Gobin L, Tassignon MJ: Keratitis and corneal scarring after UVA/riboflavin cross-linking for keratoconus. J Refract Surg 2009;25:S819-S823.

197 Spörl E, Schreiber J, Hellmund K, Seiler T, Knuschke P: Studies on the stabilization of the cornea in rabbits (in German). Ophthalmologe 2000;97:203-206.

198 Wollensak G, Spoerl E, Wilsch M, Seiler T: Endothelial cell damage after riboflavin-ultraviolet-A treatment in the rabbit. J Cataract Refract Surg 2003;29:1786-1790.

199 Wollensak G, Spörl E, Reber F, Pillunat L, Funk R: Corneal endothelial cytotoxicity of riboflavin/UVA treatment in vitro. Ophthalmic Res 2003;35:324-328.

200 Kymionis GD, Kounis GA, Portaliou DM, Grentzelos MA, Karavitaki AE, Coskunseven E, Jankov MR, Pallikaris IG: Intraoperative pachymetric measurements during corneal collagen cross-linking with riboflavin and ultraviolet A irradiation. Ophthalmology 2009;116:2336-2339.
201 Holopainen JM, Krootila K: Transient corneal thinning in eyes undergoing corneal cross-linking. Am J Ophthalmol 2011;152: 533-536.

202 Sharma A, Nottage JM, Mirchia K, Sharma R, Mohan K, Nirankari VS: Persistent corneal edema after collagen cross-linking for keratoconus. Am J Ophthalmol 2012;154: 922-926.e1.

203 Kymionis GD, Portaliou DM, Diakonis VF, Kounis GA, Panagopoulou SI, Grentzelos MA: Corneal collagen cross-linking with riboflavin and ultraviolet-A irradiation in patients with thin corneas. Am J Ophthalmol 2012;153:24-28.

204 Spadea L, Mencucci R: Transepithelial corneal collagen cross-linking in ultrathin keratoconic corneas. Clin Ophthalmol 2012;6: 1785-1792.

205 Raiskup F, Spoerl E: Corneal cross-linking with hypo-osmolar riboflavin solution in thin keratoconic corneas. Am J Ophthalmol 2011;152:28-32.e1.

206 Hafezi F, Mrochen M, Iseli HP, Seiler T: Collagen crosslinking with ultraviolet- $\mathrm{A}$ and hypoosmolar riboflavin solution in thin corneas. J Cataract Refract Surg 2009;35:621624.

207 Padmanabhan P, Dave A: Collagen crosslinking in thin corneas. Indian J Ophthalmol 2013;61:422-424.

208 Kaya V, Utine CA, Yilmaz OF: Intraoperative corneal thickness measurements during corneal collagen cross-linking with hypoosmolar riboflavin solution in thin corneas. Cornea 2012;31:486-490.

209 Stewart JM, Lee OT, Wong FF, Schultz DS, Lamy R: Cross-linking with ultraviolet-A and riboflavin reduces corneal permeability. Invest Ophthalmol Vis Sci 2011;52:92759278.

210 Tschopp M, Stary J, Frueh BE, Thormann W, de Smet J, van Bocxlaer J, Tappeiner C: Impact of corneal cross-linking on drug penetration in an ex vivo porcine eye model. Cornea 2012;31:222-226.

211 Romppainen T, Bachmann LM, Kaufmann C, Kniestedt C, Mrochen M, Thiel MA: Effect of riboflavin-UVA-induced collagen cross-linking on intraocular pressure measurement. Invest Ophthalmol Vis Sci 2007; 48:5494-5498.

212 Gkika MG, Labiris G, Kozobolis VP: Tonometry in keratoconic eyes before and after riboflavin/UVA corneal collagen crosslinking using three different tonometers. Eur J Ophthalmol 2012;22:142-152.

213 Greenstein SA, Shah VP, Fry KL, Hersh PS: Corneal thickness changes after corneal collagen crosslinking for keratoconus and corneal ectasia: one-year results. J Cataract Refract Surg 2011;37:691-700.

214 Gutierrez R, Lopez I, Villa-Collar C, Gonzalez-Meijome JM: Corneal transparency after cross-linking for keratoconus: 1-year follow-up. J Refract Surg 2012;28:781-786. 